OPEN ACCESS

Edited by:

Alvaro Sanz-Saez,

Auburn University, United States

Reviewed by:

Milan Borisev,

University of Novi Sad, Serbia Fernando Torralbo,

University of Missouri, United States

Nieves Goicoechea,

University of Navarra, Spain

*Correspondence:

Rupam Kapoo

kapoor_rupam@yahoo.com

Specialty section:

This article was submitted to

Plant Abiotic Stress,

a section of the journal

Frontiers in Plant Science

Received: 15 December 2020

Accepted: 11 May 2021

Published: 17 June 2021

Citation:

Sharma K, Gupta S, Thokchom SD, Jangir $P$ and Kapoor R (2021)

Arbuscular Mycorrhiza-Mediated

Regulation of Polyamines and Aquaporins During Abiotic Stress:

Deep Insights on the Recondite

Players. Front. Plant Sci. 12:642101.

doi: 10.3389/fpls.2021.642101

\section{Arbuscular Mycorrhiza-Mediated Regulation of Polyamines and Aquaporins During Abiotic Stress: Deep Insights on the Recondite Players}

\author{
Karuna Sharma, Samta Gupta, Sarda Devi Thokchom, Pooja Jangir and Rupam Kapoor* \\ Department of Botany, University of Delhi, New Delhi, India
}

Environmental stresses of (a)biotic origin induce the production of multitudinous compounds (metabolites and proteins) as protective defense mechanisms in plants. On account of the regulation of some of these compounds, arbuscular mycorrhizal fungi (AMF) reinforce the inherent tolerance of plants toward the stress of different origins and kind. This article reviews two specific fundamental mechanisms that are categorically associated with mycorrhiza in alleviating major abiotic stresses, salt, drought, and heavy metal (HM) toxicity. It puts emphasis on aquaporins (AQPs), the conduits of water and stress signals; and polyamines (PAs), the primordial stress molecules, which are regulated by AMF to assure water, nutrient, ion, and redox homeostasis. Under stressful conditions, AMF-mediated host AQP responses register distinct patterns: an upregulation to encourage water and nutrient uptake; a downregulation to restrict water loss and HM uptake; or no alterations. The patterns thereof are apparently an integrative outcome of the duration, intensity, and type of stress, AMF species, the interaction of fungal AQPs with that of plants, and the host type. However, the cellular and molecular bases of mycorrhizal influence on host AQPs are largely unexplored. The roles of PAs in augmenting the antioxidant defense system and improving the tolerance against oxidative stress are well-evident. However, the precise mechanism by which mycorrhiza accords stress tolerance by influencing the PA metabolism per se is abstruse and broadly variable under different stresses and plant species. This review comprehensively analyzes the current state-of-art of the involvement of AMF in "PA and AQP modulation" under abiotic stress and identifies the lesser-explored landscapes, gaps in understanding, and the accompanying challenges. Finally, this review outlines the prospects of AMF in realizing sustainable agriculture and provides insights into potential thrust areas of research on AMF and abiotic stress.

Keywords: abiotic stress, arbuscular mycorrhizal fungi, aquaporins, polyamines, salt stress, drought stress, heavy metal toxicity 


\section{INTRODUCTION}

Environmental factors like light, temperature, water, and soil status are important abiotic components that regulate the plant life cycle, and any abnormality in these factors predisposes the plants to stress, a state of altered physiology (Sade et al., 2013). Abiotic stresses, such as salinity, drought, and heavy metals (HMs), result in a $70 \%$ reduction in global crop yield worsening the dwindling equilibrium between crop production and exponential population growth (Singh et al., 2016). In addition to this, abiotic stresses, particularly salinity and HMs, depress the nutrient availability in soil and lead to nutritional disorders in plants (Juniper and Abbott, 1993; Evelin et al., 2012; Gusman et al., 2013; Gupta et al., 2021). Soil salinity and HM contamination have been demonstrated to limit the accumulation of minerals, such as $\mathrm{Ca}, \mathrm{Fe}, \mathrm{Mg}$, and $\mathrm{Zn}$ in edible parts of crop plants (Gusman et al., 2013; Chakraborty et al., 2016; Alam et al., 2019; Liu et al., 2020), consequently reducing the nutritive value of the crops. Since these minerals are essential for the human diet, any decrease in their concentrations will have a major impact on nutritional security of food and can give rise to hidden hunger, which is a grave issue especially in a scenario where the global burden of crop production and micronutrient deficiency remains alarming (FAO, 2017).

High soil salinity (>4 dS/m; Juniper and Abbott, 1993) stems from rapid uptake and translocation of $\mathrm{Na}^{+}$and $\mathrm{Cl}^{-}$ions by the plants at the expense of important nutrients such as $\mathrm{K}, \mathrm{P}$, and $\mathrm{Ca}$ and sequential translocation of these ions into the shoot tissues, thereby increasing the toxic load. Drought stress results from a moderate water loss, which, when gets extensive, results in cellular desiccation (Jaleel et al., 2009) that can cause potential loss of enzyme activity, gross disturbance of plant metabolism, and handicapped cell structure and function. Moreover, essential $(\mathrm{Cu}, \mathrm{Mn}, \mathrm{Zn}, \mathrm{Fe}, \mathrm{Mo}, \mathrm{Co}$, and $\mathrm{Ni}$ ) and non-essential (As, $\mathrm{Pb}, \mathrm{Sn}, \mathrm{Cd}, \mathrm{Hg}, \mathrm{Al}$, and $\mathrm{Cr}$ ) $\mathrm{HMs}$ also generate toxic/lethal effects on plant growth and metabolism by the inhibition of nutrient assimilation and biomass accumulation, degradation of chlorophyll, passivation of enzymes, disturbed water balance, and senescence. These stresses exacerbate the risk to food security of the world with a teeming population that is projected to mushroom to 11.2 billion by the end of the century (Roser et al., 2013).

Most of the mitigation strategies that are employed to cope with adverse impacts of abiotic stress are either long term, such as breeding stress-tolerant varieties, or are inaccessible or costly to farmers (Bharti et al., 2017). We endeavor to usher sustainable crop production in a way that does not cause economical brunt on farmers. However, noteworthy is the fact that, despite considerable research into the effects of salt and drought on crops, the release of abiotic-tolerant/resistant cultivars has not been commensurate. The reason is most likely due to the complex nature of the effect of stressors on crop plant; as in a multigenic trait, like tolerance to stress, the hierarchy of different aspects of tolerance may differ among and within species (Flowers and Yeo, 1995; Flowers et al., 1997). Abiotic tolerance is way too complex to be easily amenable to refinement through the selection of a trait per se. On that account, arbuscular mycorrhizal fungi (AMF) emerge to the occasion as a group of potential stress mitigators in plants owing to their tolerance to extremities, diversity in genetic makeup, ubiquity, and promiscuous interaction with plants and soil (Bharti et al., 2017). In view of that, the deployment of AMF to alleviate abiotic stress in plants is a better, an economical, and an effective agronomic option.

Intrinsic protective mechanisms aside, plants can counteract environmental stress by associating with AMF that form a promiscuous mutualistic relationship with the majority of terrestrial plants ( $>100,000$ species) (Wang and Qiu, 2006). AMF orchestrate various biochemical and physiological pathways that coordinate to impart tolerance to the host plant. They maintain nutrients, ions, and redox homeostasis; enhance water acquisition by serving as extended plant roots, ensure photosynthetic efficiency and osmoregulation, and reinforce antioxidant metabolism (Evelin et al., 2019). Much of these protective roles conferred by mycorrhizal associations during stress can be ascribed to multiple factors, of which AMFmediated modulation of polyamines (PAs) and aquaporins (AQPs), the recondite players in abiotic stress mitigation, are discussed at length in this review.

Due to their positively charged characteristics, PAs interact with anionic functional groups of membranes and proteins (Slocum et al., 1984). They influence the stability and permeability of cell membranes by the formation of electrostatic bonds with phospholipid head groups (Besford et al., 1993). They have also been reported to prevent loss of chlorophyll from thylakoid membranes by stabilizing the photosystem complexes (Popovic et al., 1979). PAs enhance osmolyte and antioxidant production and interact with other important metabolic routes that are of the essence to stress tolerance in plants. As highlighted in the review, there exists coordination between AMF and the PA metabolism (Sannazzaro et al., 2007; Cicatelli et al., 2010; Wu et al., 2012a; Abdel-Fattah et al., 2013; Talaat and Shawky, 2013; Zhang et al., 2020). However, the understanding of an exact mechanism underlying AMF-mediated modulation of PA pool in relation to salt/drought/HM tolerance is an uncharted area; ergo, merits more research for deeper insights and practical implications. AQPs are intrinsic membrane proteins that facilitate transcellular passive conduction of water and neutral molecules, a significant role that is implicated in the alleviation of water stress. Studies demonstrating the differential regulation of AQP genes in AMF-inoculated plants under water-deficit conditions (salinity and drought) consolidate the role of AMF in helping plants combat water scarcity, but the mechanisms underlying these responses at cellular and molecular level still remain elusive. However, the role of AQPs in combating metal stress in plants is limited to few records and demands extensive exploration. Information on the direct relationship among the two biomolecules (PA and AQP) and AMF per se is sketchy. However, it can be speculated that AMFmediated PA homeostasis could be involved in regulating AQP protein abundance, thereby contributing to the maintenance of plant-water relations; although no concrete evidence exists to reinforce this postulation. Future research should venture into such investigations to expand the dimensions and depth of our understanding on this subject. 
Along this review, we explore and analyze the contribution of various studies on the role of AMF in the modulation of the PA metabolism and AQP gene expression as significant mechanisms to impart tolerance to abiotic stresses in plants. As devising strategies that are oriented to improve stress recovery and stress resistance in plants become an enormous challenge, this review will outline the prospects of AMF in realizing sustainable agriculture.

\section{POLYAMINE METABOLISM AND THEIR CROSS TALK WITH OTHER METABOLIC ROUTES INVOLVED IN STRESS TOLERANCE}

Polyamines are ubiquitous biostimulants, with low-molecularweight, that participate in an array of plant growth, developmental and defense processes under stressful conditions (Chen et al., 2019). Triamine spermidine (Spd), tetramine spermine (Spm), and their precursor, diamine putrescine (Put) are the principal free PAs found in plants (Galston and Sawhney, 1990).

PA metabolism: Putrescine occupies a central position in the common PA biosynthetic pathway whose biosynthesis transpires via two parallel routes: (1) arginine-derived pathway involving arginine decarboxylase (ADC) and (2) ornithinederived pathway involving ornithine decarboxylase (ODC) (Hanfrey et al., 2001; Kakkar and Sawhney, 2002). The aminopropyl residues that are successively incorporated into the Put skeleton to yield Spd and Spm are furnished from decarboxylated S-adenosyl methionine (dcSAM). The addition of the aminopropyl moieties to the Put precursor is effectuated by the enzymes Spd synthase (SPDS) and Spm synthase (SPMS), respectively. The catabolism of $\mathrm{PA}$ is impelled by the action of two major classes of amine oxidases: $\mathrm{Cu}$-containing diamine oxidase (DAO) and flavoprotein-containing PA oxidase (PAO). Stringent regulation of cellular PA titers is imperative for evoking responses to environmental cues (such as stress) through an intricate crosstalk with other metabolic pathways that are involved in the synthesis of stress signals and metabolites [ethylene, proline, gamma-aminobutyric acid (GABA), nitric oxide (NO), and abscisic acid (ABA)] involved in amplifying the defense response of plants against encountered stress (Figure 1).

Cross talk of PA metabolism with stress-defensive metabolites: Ethylene and PAs are interlinked by a common precursor, Sadenosyl methionine (SAM). The deviation of metabolic flux from ethylene synthesis toward PA synthesis confers tolerance as ethylene temporarily and reversibly hinders cell cycle and speeds up senescence in plants that are under the grip of environmental stress (Even-Chen et al., 1982; Dubois et al., 2018). The synthesis of proline is also in strong correlation with the PA metabolic route by virtue of the common precursor, glutamate (Sannazzaro et al., 2007; Mohapatra et al., 2009). A significant contribution of Put degradation by DAO to proline accumulation has also been reported. The ensuing accumulation of proline by the PA oxidation mediates osmoprotection and serves as a nitrogen reserve that can be exploited by the plant during recovery. Stress-triggered changes in the level of PAs translate into the alteration in cellular content of a non-protein amino acid, GABA, which further boosts the antioxidant capacity and synthesis of protective osmolytes, proline and soluble sugars like trehalose, that are essential for cellular osmotic adjustments (Wang et al., 2017; Priya et al., 2019). PAs also induce the production of a signaling molecule, NO (Tun et al., 2006), that may bridge the PA-mediated stress response with other mediators of stress. NO also, in turn, increases the PA titers under stress (Tailor et al., 2019). PAs, in alliance with their catabolic products, $\mathrm{H}_{2} \mathrm{O}_{2}$ and $\mathrm{NO}$, formed via different metabolic routes, appear to act cooperatively to fine-tune ABA responses in stomatal closure during physiological drought conditions (Yamasaki and Cohen, 2006). The presence of ABA-responsive elements, ABRE (namely, ABRE-related motifs) in the promoter sequence of PA biosynthetic genes has reinforced the notion that the participation of PAs in stress tolerance is ABA-dependent. PAs, precisely Put, and ABA are invested in a positive feedback circuit within which they mutually foster production of each other to ameliorate acclimation of plant to abiotic stress (Alcázar et al., 2010). Put activates the NCED gene that prompts the ABA accumulation via zeaxanthin. This further activates the ABRE elements that stimulate AREB/ABF transcription factors (TFs). These TFs, in turn, regulate the $A D C$ gene and direct the synthesis of principal PA, Put (Espasandin et al., 2014) (Figure 1). Additionally, ABA can encourage methionine to produce a generous amount of higher PAs via dcSAM (Li et al., 2020).

Interaction among PAs, phytohormones, and other metabolites: There exists a highly conserved pathway that is expressed in plants subjected to stress, integrating different phytohormones that regulate plant processes via changes in glutamate metabolism (Podlešáková et al., 2018); and therefore, in the PA metabolism, regulating the reactive oxygen species (ROS) responses and NO production, which successively also regulate phytohormone signaling in stressed plants (Freschi, 2013). In general, PAs and plant hormone biosynthesis and signaling are closely related (reviewed by Anwar et al., 2015). Their extensive scrutiny of published data revealed that generally Put is positively correlated with the expression of genes regulating ABA biosynthesis (Alcazar et al., 2005; Singh et al., 2018) but have an inverse effect on hormones, such as ethylene, jasmonic acid, and gibberellic acid (GA) (Alcazar et al., 2005; Cuevas et al., 2008) while the action of Spd is totally antipodal to that (Radhakrishnan and Lee, 2013a; Li Z. et al., 2016). Conversely, Spm promotes the expression of genes involved in ethylene and jasmonate biosynthesis (Ozawa et al., 2009; Gonzalez et al., 2011) while downregulating those for gibberellins (Gonzalez et al., 2011) and ABA biosynthesis (Radhakrishnan and Lee, 2013b). Spd is found to positively regulate salicylic acid (SA) signaling (Lazzarato et al., 2009), and those of cytokinins and auxins are linked to Spm action (Anwar et al., 2015; Sharma et al., 2019). Overall, the nature of these cross-talks between PAs and phytohormones varies with the set of PAs and the hormone involved, and also with the developmental stage of the plant and abiotic conditions to which it is subjected. Mycorrhizal plants perceive the stress cues that trigger the modification in the endogenous levels of phytohormones and/or PA (phyto-regulators). This influences 


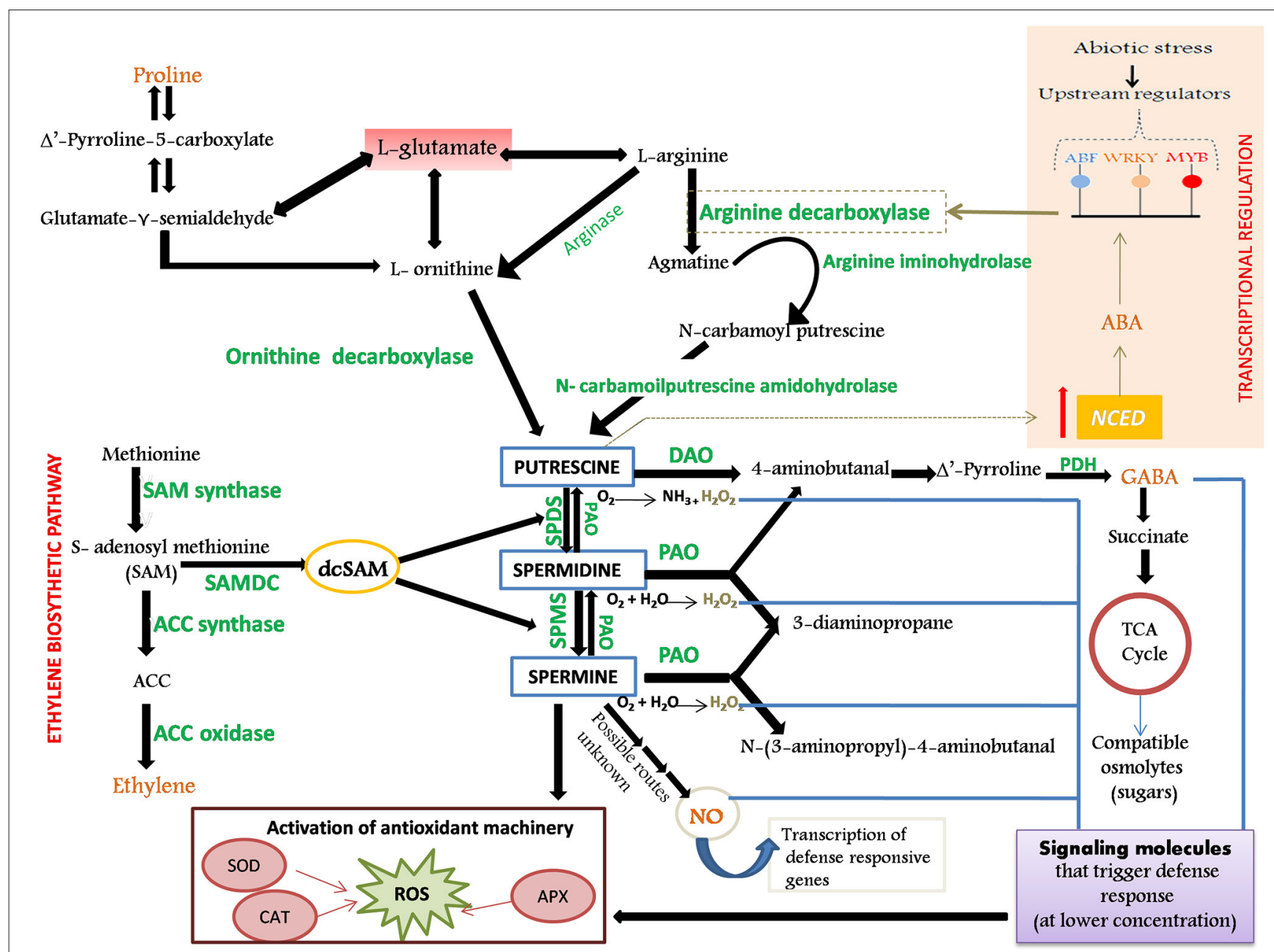

FIGURE 1 | Schematic representation of biosynthesis and catabolism of polyamines (PAs), their role in the activation of defense response in plants and cross-talk with stress-defensive metabolites. The enzymes involved in the metabolic processes are shown in green color. Putrescine (Put), the central molecule of PA biosynthesis, can be synthesized either by arginine (by ADC) or by ornithine (by ODC) derived pathway. Synthesis of diamine spermidine (Spd) and tetramine spermine (Spm) is brought about by the subsequent addition of aminopropyl groups (furnished from the decarboxylated penultimate precursor of ethylene, dcSAM) to the Put skeleton, and is catalyzed by SPDS and SPMS, respectively. Degradation of Put is catalyzed by DAO and that of Spd and Spm by PAO. PAs, along with their catabolic by-products (GABA, $\mathrm{H}_{2} \mathrm{O}_{2}$, and NO), serve as stress messengers and participate in the reinforcement of antioxidant machinery. Production of GABA from PA further boosts the production of compatible osmolytes (such as sugars) under stress. Put and Pro are linked by the common precursor glutamate and share precursor-product relationship regulated by DAO and GABA. Through possibly unknown mechanisms, both PA and NO are found to increase production of each other during stress. Spd possibly intensifies NOS activity that boosts NO production. Put and abscisic acid (ABA) are invested in a positive feedback circuit; Put activates NCED gene that triggers ABA accumulation, which further activates TFs that in turn regulate the ADC gene. ODC, Ornithine Decarboxylase; ADC, Arginine Decarboxylase; DAO, Diamine Oxidase; PAO, Polyamine Oxidase; PDH, Pyrroline Dehydrogenase; SPMS, Spermine Synthase; SPDS, Spermidine Synthase; ACC, 1-aminocyclopropane-1-carboxylic acid; NO, Nitric Oxide; GABA, Gamma-Aminobutyric Acid; $\mathrm{H}_{2} \mathrm{O}_{2}$, Hydrogen Peroxide; dcSAM, decarboxylated S-Adenosyl Methionine; Pro, Proline; NOS, Nitric Oxide Synthase; NCED, 9-Cis-Epoxycarotenoid Dioxygenase.

the expression of genes involved in primary metabolism and those relating to amino acid metabolism (proline, GABA, and glycine betaine), carbohydrate metabolism (trehalose and sucrose), and antioxidant metabolism [ascorbate-glutathione (AsA-GSH) cycle and enzymatic antioxidant defense]. AMFprotected plants exhibit reinforced PA production (Sannazzaro et al., 2007; Evelin et al., 2013), upregulated osmolyte production (Evelin et al., 2013; Garg and Saroy, 2020), and regulated synthesis of phytohormones (Shaul-Keinan et al., 2002; Khalloufi et al., 2017; Ren et al., 2018), all of which might potentially interconnect at various levels and ameliorate the tolerance mechanism for cumulative stress response (Hashem et al.,
2018). Different phytohormones influence overlapping processes such that the result of phytohormone action relies on a certain hormone combination rather than on their discrete actions (Iqbal et al., 2014).

\section{AMF-MEDIATED MODULATION OF POLYAMINES AND THEIR RESPONSES UNDER STRESS}

The close association of PAs with the defense response of plants is ascribed to multiple reasons: (1) transcriptional activity of 
PA biosynthetic genes [ADC, ODC, SPDS, SPMS, and SAM decarboxylase $(S A M D C)$ ] and catalytic ability of the enzymes that participate in the PA metabolism are reinforced in the presence of stress, (2) induced suppression of PA synthesis by inhibitors such as difluoromethyl ornithine (DFMO), difluoromethyl arginine (DFMA), and cyclohexylamine (CHA) or by knocking down/out PA synthesizing genes, corresponds to a compromised defense response (Urano et al., 2003), (3) abundance of free and conjugated PAs in stress-tolerant cultivars under stressful conditions (Zapata et al., 2004), and (4) overexpression of PA biosynthetic genes results in a concomitant increase in the ability of plants to counter and acclimate to stress (Wen et al., 2008). Most studies till now have reiterated the positive impact of exogenous application of PAs on root/shoot architecture, development, and stress response in plants (for instance, Panax ginseng; Parvin et al., 2014, Zoysia japonica Steud; Li S. et al., 2016; Bakraii citrus seedlings; Khoshbakht et al., 2018, and Cucumis sativus; Wu et al., 2018). However, it is increasingly becoming a realm of scientific interest to strategize techniques by which endogenous PA production can be boosted so as to improve the overall development of plant as well as to magnify stress adaptiveness. Transgenic approaches oriented toward overexpressing PA biosynthetic genes and manipulating the intertwined metabolic web in a way that directs the metabolic flux toward the synthesis of stress messengers and scavengers are deemed as efficient techniques. Albeit they are successful, these high-throughput approaches are beyond the financial frontiers of many developing and low-middle-income nations. In this respect, use of AMF to optimize the PA metabolism emerges as an economically effective agronomic option. As aforementioned, AMF ensure the PA homeostasis that further helps in stress mitigation by the maintenance of $\mathrm{pH}$ and ion homeostasis, production of osmolytes and improvement of plant water status, ROS scavenging, stability of membrane and photosystem framework, modified expression of stressresponsive genes, regulation of root plasticity (Talaat and Shawky, 2013) (Figure 2), and the regulation of ribosomes, amino acids, and energy metabolism (Li et al., 2018). The mediation of stress tolerance using AMF by reinforcing the PA metabolism as a strategy is discussed in the following sections.

\section{Salt Stress}

High soil salinity directly results in various downstream stresses, viz., hyperionic stress, physiological drought, hyperosmotic stress, and nutrient imbalance (Evelin et al., 2009; Porcel et al., 2012). Several studies have dealt with the association of AMF and the PA metabolism in plants to improve tolerance to salt stress (Sannazzaro et al., 2007; Echeverria et al., 2013; Evelin et al., 2013; Talaat and Shawky, 2013; Abeer et al., 2014).

Sannazzaro et al. (2007) reported an increase in the $\mathrm{Spd}+\mathrm{Spm} /$ Put ratio in salinity-stressed roots of Lotus glabra and ascribed it as a mechanism deployed by AMF to mediate the defense response of plants under unfavorable conditions. Lesser free Put in the leaves could be postulated as a deviation of the metabolic pool either toward the synthesis of higher PAs, Spd, and Spm (that have better protective capacity than Put by virtue of additional $\mathrm{NH}_{2}$ groups) or toward proline synthesis (as glutamate is the common precursor of proline and PA, Figure 1). However, the validation of this hypothesis would require exhaustive investigation to elucubrate the relationship among mycorrhization, root architecture, and the balance between primary and secondary metabolism. Additionally, they concluded that both mycorrhizal and non-mycorrhizal plants would be equally stressed since they accumulate similar proline contents. Moreover, no correlation was observed between an increased $\mathrm{Spd}+\mathrm{Spm} / \mathrm{Put}$ ratio and the proline accumulation (Sannazzaro et al., 2007). Contrastingly, the AMF inoculation leads to a significant reduction in DAO and PAO activity in salt-stressed wheat plants that accounted for increased content of free Put, Spd, and Spm, and technically highest Put level, which boosted the fitness of plants to salt stress and influenced the ROS-scavenging antioxidant mechanism in inoculated plants (Talaat and Shawky, 2013). Likewise results were obtained in inoculated Trigonella foenum-graecum (Evelin et al., 2013), Lotus tenuis (Echeverria et al., 2013), and Vicia faba (Abeer et al., 2014) plants, wherein AMF application augmented the free PA titers along with other favorable influences on plant metabolism (Table 1). Premised on a tight correlation of Put synthetases and root architecture, it can be argued that AMF-triggered root Put (and not Spm and Spd) refines root traits, hence fostering better nutrient acquisition and improved drought acclimation, as confirmed by Wu et al. (2012b) in Citrus tangerine plants.

The synergistic role of PAs and AMF in helping the plant combat stress is also substantiated by mounting evidence that demonstrates how PA and AMF mutually foster each other under stress and concomitantly exert their beneficial effects to make plants more resilient to stress (Figure 3), as the dual administration of AMF and PA is found to be more efficient in maintaining/improving phenotype of the plant under stress than AMF inoculation or PA administration alone (Niemi et al., 2006; Ibrahim et al., 2011; Abdel-Fattah et al., 2013). A comprehensive conclusion can be squeezed out from all the investigations carried out hitherto; there exists a tightly regulated coordination between AMF and the PA metabolism that is committed to refine physiological plasticity of plants and resilience to assure its survival under unfavorable environments. These implications may be of practical importance in realizing the economically feasible, yet efficient, development of salttolerant crops.

\section{Drought Stress}

Notwithstanding the precise role of PAs in abiotic stress tolerance and the intimate mechanisms of such an effect are uncertain, there has been mounting evidence evincing the role of PAs in drought-stressed plants. Several studies corroborate the fact that the PA reservoir of plants corresponds to drought stress tolerance. For instance, Nahar et al. (2016) reported in Vigna radiata the Spm-mediated upregulation of antioxidant genes and decreased methylglyoxal toxicity by the activity of refined glyoxalase system. This system plays a critical role in counteracting oxidative stress by recycling reduced GSH, which is entrapped by methylglyoxal, consequently maintaining GSH homeostasis. Higher PA levels were recorded in waterstressed wheat, as postulated to be responsible for drought 


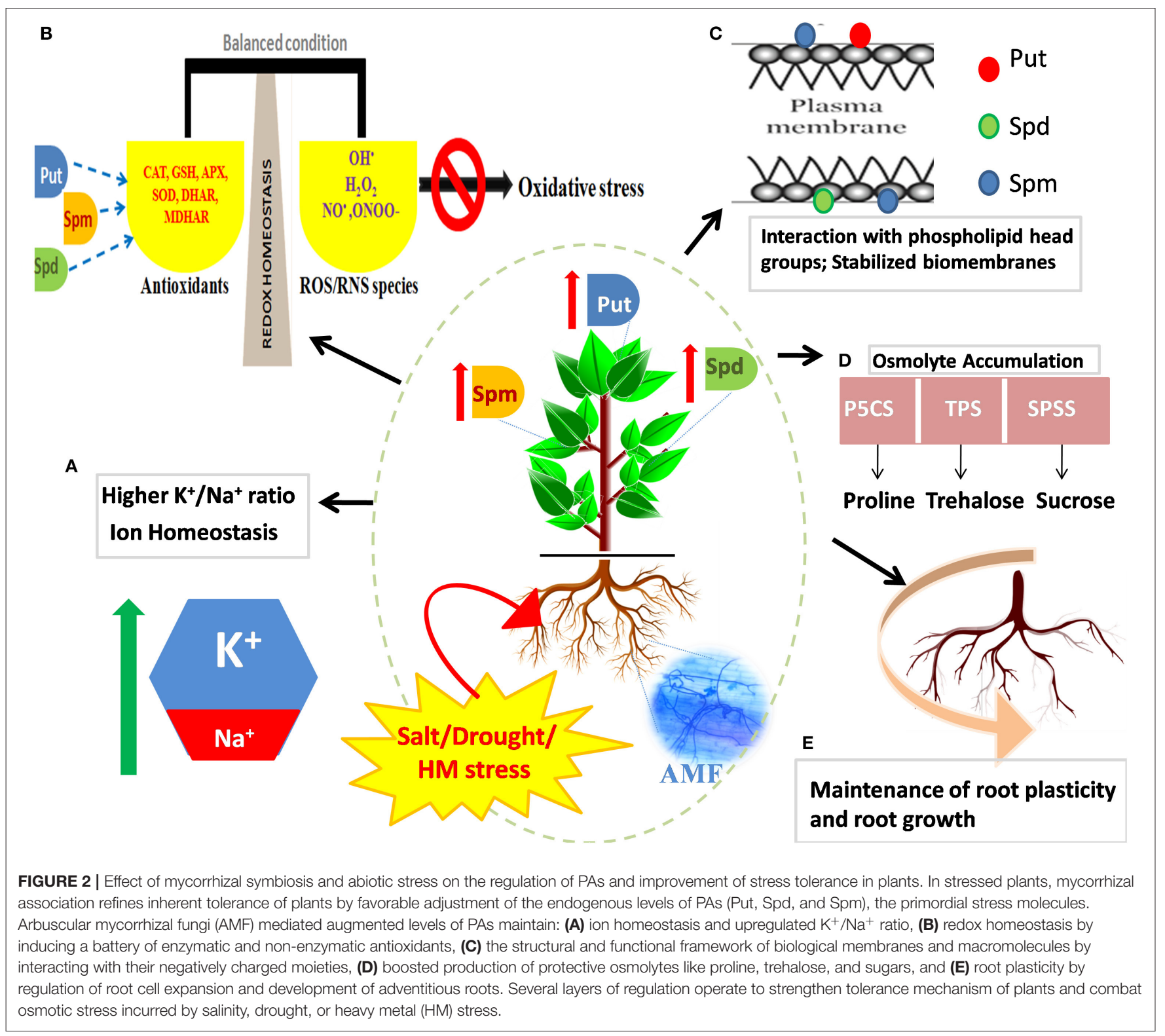

tolerance and grain filling (Liu et al., 2016). PAs moderate the evolution rate of ethylene (antagonistic behavior), which might have accounted to better grain filling in wheat plants. In a pioneering study by Hura et al. (2015), drought stress tolerance in triticale during late developmental stages (from tillering to anthesis) was associated with specific accumulation of cell membrane-bound PAs and decreased content of free PAs. This could be accredited to the role of PAs in the reinforcement of plant cell wall under stress. Besides, PAs are also capable of regulating stomatal movements under drought stress conditions by encumbering inward rectifying $\mathrm{K}^{+}$channels (KIRC) (Liu et al., 2000) (Figure 2). The binding of Put ions to the KIRC site propels the outward displacement of $\mathrm{K}^{+}$ions and further retards $\mathrm{K}^{+}$movement across the channel (Chen et al., 2020). PAs are significant targets in AMF-mediated drought stress regulation. However, inconsistency in $\mathrm{PA}$ accrual patterns has been observed in AM plants in response to water deficit. The first pioneering study in reference to this was conducted by Goicoechea et al. (1998) wherein the inoculation of waterstressed alfalfa plants with Glomus fasciculatum resulted in the following: (1) an increment of free Spm and Spd levels, which might serve as a nitrogen reserve that can be used to fulfill immediate energy demands of the plants soon after it recuperates from stress and (2) a higher enhancement of PA concentration in leaves than that in roots, which might be due to a high transpiration rate observed in drought-stressed plants that fostered a long-distance transport of PAs from root to shoot via transpiration stream. Also, the free Spd contents of stressed AM plants were closely correlated with proline levels. In contrast to that, Zhang et al. (2020) observed that besides boosting 
TABLE 1 | Effects of arbuscular mycorrhizal fungi (AMF) inoculation on modulation of polyamine ratio under abiotic stresses.

\begin{tabular}{|c|c|c|c|c|}
\hline Abiotic stress & Plant species & AMF Species & Effect on polyamine ratio & References \\
\hline $\begin{array}{l}\text { SALT STRESS } \\
(0 \text { and } 200 \mathrm{mM})\end{array}$ & Lotus glaber & $\begin{array}{l}\text { Glomus } \\
\text { intraradices }\end{array}$ & $\begin{array}{l}\uparrow(\text { Spd }+ \text { Spm)/Put ratio; } \uparrow \text { Put in shoots of tolerant } \\
\text { plants, } \uparrow \text { Spd and Spm in both tolerant and } \\
\text { sensitive plants }\end{array}$ & Sannazzaro et al., 2007 \\
\hline $\begin{array}{l}\text { SALT STRESS } \\
(0,50,100 \text {, and } 200 \mathrm{mM})\end{array}$ & $\begin{array}{l}\text { Trigonella foenum- } \\
\text { graecum }\end{array}$ & G. intraradices & $\begin{array}{l}\uparrow P \text { ut, } \uparrow S p d, \uparrow S p m \text {, Increased content of other } \\
\text { osmolytes (total soluble sugars, proline, } \\
\text { glycine betaine) }\end{array}$ & Evelin et al., 2013 \\
\hline $\begin{array}{l}\text { SALT STRESS } \\
(0 \text { and } 150 \mathrm{mM})\end{array}$ & Lotus tenuis & G. intraradices & $\begin{array}{l}\text { AM salt-stressed plants showed a higher root PA } \\
\text { (Spm, Spd, Put) level than their corresponding } \\
\text { non-AM controls; no significant effect of AM under } \\
\text { salt stress on total, root, stem, and leaf free PA } \\
\text { contents in comparison to control plants }\end{array}$ & Echeverria et al., 2013 \\
\hline $\begin{array}{l}\text { SALT STRESS } \\
\left(4.7 \text { and } 9.4 \mathrm{dS} \mathrm{m}^{-1}\right)\end{array}$ & $\begin{array}{l}\text { Triticum aestivum (Giza } \\
\text { 168, Sids 1) }\end{array}$ & $\begin{array}{l}\text { Mixture of Glomus } \\
\text { spp. }\end{array}$ & $\begin{array}{l}\text { Significant reduction in DAO and PAO activities } \\
\text { under salt stressed plants; } \uparrow \text { Put, } \downarrow \text { Spm and Spd } \\
\text { in Giza } 168, \downarrow \text { Put, } \uparrow \text { Spm and } \uparrow S p d \text { in Sids } 1\end{array}$ & $\begin{array}{l}\text { Talaat and Shawky, } \\
2013\end{array}$ \\
\hline SALT STRESS $(0,50$, and $100 \mathrm{mM})$ & Vicia faba & $\begin{array}{l}\text { Funneliformis } \\
\text { mosseae, } \\
\text { Rhizophagus } \\
\text { intraradices, and } \\
\text { Claroideoglomus } \\
\text { etunicatum }\end{array}$ & $\begin{array}{l}\text { Significant increase in Put, Spd, Spm levels under } \\
\text { all conditions of salinity, with maximum increase in } \\
\text { Put concentration (under } 100 \text { mM treatment) }\end{array}$ & Abeer et al., 2014 \\
\hline $\begin{array}{l}\text { DROUGHT STRESS ( } 2 \text { cycles of } \\
\text { moisture stress) }\end{array}$ & Medicago sativa & G. fasciculatum & $\begin{array}{l}\text { Higher free polyamine (Spd and Spm) content in } \\
\text { symbiotic water-stressed plants; No significant } \\
\text { enhancement of polyamine concentration in roots }\end{array}$ & $\begin{array}{l}\text { Goicoechea et al., } \\
1998\end{array}$ \\
\hline $\begin{array}{l}\text { DROUGHT STRESS (45-50\% max } \\
\text { field water capacity) }\end{array}$ & Poncirus trifoliata & G. mosseae & $\begin{array}{l}\downarrow \text { Put and Spd, } \uparrow \text { Spm content, } \uparrow \text { SPMS activity in } \\
\text { drought stressed AM plants }\end{array}$ & Luo, 2009 \\
\hline $\begin{array}{l}\text { DROUGHT STRESS ( } 50 \% \text { of max. } \\
\text { water holding capacity) }\end{array}$ & P. trifoliata & F. mosseae & $\begin{array}{l}\uparrow \text { Put and Cad, } \downarrow \text { Spd and Spm concentrations, } \\
\uparrow P A \text { catabolic enzyme activity (CuAO; PAO) and } \\
\text { Put-synthases (ODC and ADC) }\end{array}$ & Zhang et al., 2020 \\
\hline $\begin{array}{l}\text { DROUGHT STRESS (mild T1 and } \\
\text { moderate T2 drought) }\end{array}$ & Zea mays & R. irregularis & $\begin{array}{l}\text { Significantly, } \downarrow \text { Put content in water stressed (T1 } \\
\text { and T2) AM plants, } \uparrow D A O \text { and } \uparrow G A B A T \text { activity, } \\
\uparrow G A B A \text { accumulation }\end{array}$ & Hu and Chen, 2020 \\
\hline $\begin{array}{l}\text { DROUGHT STRESS (soil WW status } \\
(18.08 \%)\end{array}$ & P. trifoliata & F. mosseae & $\begin{array}{l}\uparrow A D C, \uparrow O D C, \uparrow S P M S, \uparrow S P D S, \uparrow D A O, \uparrow P A O \\
\text { activity. } \uparrow \text { precursor of PA (agmatine, L-ornithine } \\
\text { and SAM), } \uparrow \text { Put, } \uparrow \text { Cad, } \downarrow \text { Spd }\end{array}$ & Zou et al., 2021 \\
\hline HEAVY METAL STRESS (Cd) & Plantago lanceolata & G. fasciculatum & $\begin{array}{l}\text { No significant difference in leaf PA ratio between } \\
\text { mycorrhizal and non-mycorrhizal plants. } \\
\text { Mycorrhizal roots registered lower } \\
\text { (Put/Spd+Spm) ratio }\end{array}$ & Parádi, 2003 \\
\hline HEAVY METAL STRESS (Cu and Zn) & Populus alba & $\begin{array}{l}\text { G. mosseae and } \\
\text { G. intraradices }\end{array}$ & $\begin{array}{l}\text { Induction of PaSPDS1 and PaSPDS2 and } \\
\text { PaADC; } \uparrow \text { free and conjugated PA titers in stressed } \\
\text { AM plants; } \uparrow \text { stabilization of heavy metals in soil }\end{array}$ & Cicatelli et al., 2010 \\
\hline HEAVY METAL STRESS (Pb) & $\begin{array}{l}\text { Calopogonium } \\
\text { mucunoides }\end{array}$ & G. etunicatum & $\begin{array}{l}\text { Mycorrhization influenced free amino acid profile in } \\
\text { leaves; resulted in depleted arginine content, } \\
\text { prioritizing PA synthesis over protein metabolism }\end{array}$ & Souza et al., 2014 \\
\hline
\end{tabular}

growth traits and AQP expression in Poncirus trifoliata plants, Funneliformis mosseae augmented the cellular concentration of specifically two diamines, Put and cadaverine (Cad), and diminuted the concentrations of root Spd and Spm under waterdeficit conditions. This is ascribed to a concomitant increase in the activity of Put-synthases $(A D C$ and $O D C)$ and Put-oxidases (PtPAO1, PtPAO2, and PtPAO3) that convert Spd back to Spm and further to Put, by successive deamination (Mo et al., 2015). The upregulation of $P A O$ expression is important to stimulate stress responsiveness in plants probably because it results in the production of $\mathrm{H}_{2} \mathrm{O}_{2}$, which, when present in moderate amounts, serves as a ligand in stress signaling (Sequera-Mutiozabal et al., 2017).

Another study on P. trifoliata inoculated with Glomus mosseae and subjected to drought stress exhibited substantially lowered concentrations of Put and Spd and significantly elevated levels of Spm in inoculated (vs. non-inoculated) plants, thereby advocating the essential role of Spm in trifoliate orange (Luo, 2009). The increased titers of free Spm could be explained by the higher activity of the SPMS gene and drought-spurred reduction of its metabolic precursors, Put and Spd. Better protective role of higher PAs (owing to the additional amine 


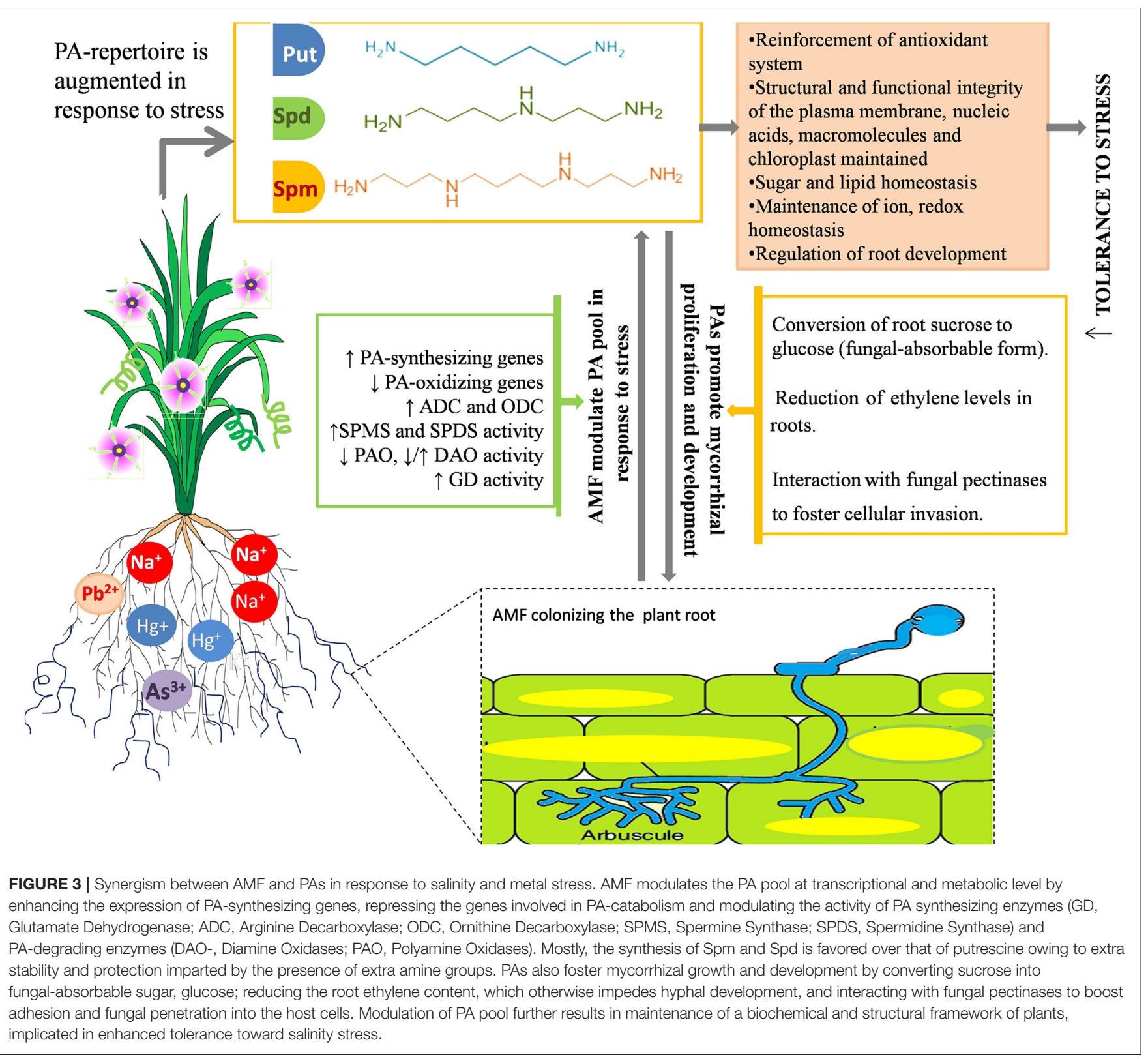

groups) could also offer a good explanation for the higher Spd concentration obtained. The results of an experiment on maize seedlings exposed to water-deficit conditions suggested that Put oxidation into GABA [by the activity of copper amine oxidase $(\mathrm{CuAO})]$ was the target pathway in AM-facilitated regulation of drought tolerance (Hu and Chen, 2020). GABA shunt is vital for $\mathrm{C} / \mathrm{N}$ homeostasis in plants (Shelp et al., 2012) and drought acclimation (Mekonnen et al., 2016). Moreover, the activity of GABA transaminase (GABAT) was significantly high in AM roots under drought. GABAT converts GABA into a subsequent substrate, succinate, which is consumed in the tricarboxylic acid cycle (TCA) cycle to synthesize carbohydrates. In a recent study by Zou et al. (2021), AMF-regulated PA homeostasis in the roots of $P$. trifoliata plants was found to be associated with enhanced tolerance against soil moisture deficit stress (SMDS). Mycorrhizal plants exhibited a significantly higher concentration of PA precursors, L-ornithine, agmatine, and SAM, increased Put and Cad, and reduced Spd content. In response to SMDS, AMF colonization augmented the activities of PA-synthetic (ADC, ODC, SPMS, and SPDS) and catabolizing (PAO and DAO) enzymes with much less degree of damage to the membrane and lower generation of ROS vis-à-vis nonmycorrhizal plants (Table 1). It can be speculated from the studies so far that the accrual pattern of PAs may totally vary depending on the type of host plant, the interacting AMF partner, the degree, duration, and nature of stress, and most importantly, the developmental stage and tissue of the plant under investigation; all these factors might account for 
the variation in free and/or conjugated PA pool observed in different plants.

The inherent and AMF-facilitated modulation of PA titers may behave either as an indicator or a harbinger (to communicate the perceived environmental cues) to modify spatio-temporal response of plants to stress (Rangan et al., 2014). That being said, further studies should be dedicated to unraveling the molecular signaling pathways of AM-induced regulation of these metabolic hubs. With the advent of forward and reverse genetic approaches, the functional essence of PAs in stress acclimation has been elucidated to some extent. However, a straight cause-and-effect relationship between the accumulation of PAs and drought stress is not firmly established yet (Pál et al., 2015). The knowledge acquired so far about the AMF-mediated modulation of PAs has constructed a strong case for future studies earmarked for vigilant analyses of fungal genes contributing to the modulation of PA pool upon stress exposure. High-throughput investigations involving transcriptomics, metabolomics, and microarray approaches along with a careful analysis of coordinating partners of PA metabolic enzymes will be a great deal of help in better understanding the mechanism of stress tolerance/resistance and whether it involves PA-induced epigenetic changes in the plant cells.

\section{Heavy Metal Stress}

In the process of phytoremediation, many plant-associated microbes reinforce the metal detoxification capacity of the plants (microbe-assisted phytoremediation). HM-contaminated soils can be redeemed and revegetated by using AMF that can potentially expedite the phytostabilization and phytoextraction process (Khalid et al., 2021). The potential of AMF as an ameliorator of HM toxicity has been well-proved and promoted (Christie et al., 2004; Bai et al., 2008; Merlos et al., 2016; Sharma et al., 2017; Gupta et al., 2021). Fungus-assisted phytoremediation is deemed as the most befitting and ecofriendly technology for the redemption of HM polluted soil (Khalid et al., 2021). Among various recognized mechanisms deployed by AMF for the prevention of HM uptake by plants (metal immobilization, modulation of metal transporter activity, and production of organic acids and glomalin), the regulation of the PA metabolism under metal stress is inconsiderably explored (Ezawa et al., 2002; Smith and Read, 2008; Chen et al., 2012; Tajti et al., 2018). PAs can stimulate metal chelation, boost antioxidant defense, maintain hormone homeostasis, and ensure membrane stability (Tajti et al., 2018). The stress mitigatory roles of PAs explain their inherent regulation during metal stress.

In cadmium-treated $(\mathrm{Cd})$ and copper-treated $(\mathrm{Cu})$ wheat leaf segments, a respective increase and decrease in Put and Spm concentration were obtained (Groppa et al., 2007). Such results might be attributed to the following: (1) accelerated PA (Spd and Spm) degradation into Put by higher PAO activity or (2) higher SAM flux toward ethylene metabolism, formation of which is detrimental to higher PAs. Resultantly, the reduction of Put to Spd and Spm was hampered in spite of Put availability. Similar fluctuations in PA titers have been observed in $\mathrm{Cu}$-stressed rice (Lin and Kao, 1999), Cd-stressed Potamogeton crispus L. (Yang et al., 2010), and chromium- (Cr) stressed P. trifoliata (Shahid et al., 2018), etc. Besides, exogenous feeding of PAs also refines the resistance of plants to HM stress (Rady and Hemida, 2015; Nahar et al., 2016; Taie et al., 2019). Garg and Saroy (2020) demonstrated that the combined application of AMF (Rhizoglomus intraradices) with PAs furnished a remarkable improvement in biomass (root and shoot) yield of plants, nutrient acquisition, ureids and trehalose accumulation, and nodulation potential in Cajanus cajan under nickel (Ni) stress.

A plethora of reports on both AMF-mediated and PAmediated increase in oxidative defense strategy, such as the reinforced activity of enzymes participating in AsA-GSH cycle, contributing to stress tolerance in plants, exist in the literature (to cite a few, Garg and Bhandari, 2016, Tseng et al., 2013; Liu et al., 2017; Hashem et al., 2018). In a recent study, Saroy and Garg (2021) analyzed the effectiveness of AMF and PAs in modulating the AsA-GSH cycle in two genotypes of C. cajan varying in their $\mathrm{Ni}$ tolerance. They found out that exogenous co-supplementation of PAs (mainly Put) and $R$. intraradices contributed the most in upsurge in the activity of enzymes of AsA and GSH pool [ascorbate peroxidase (APOX), monodehydroascorbate reductase (MDHAR), dehydroascorbate reductase (DHAR), glutathione reductase (GR)] and also improved GSH/glutathione oxidized (GSSH) ratio, consequently providing tolerance against the HM-induced oxidative damage in pigeon pea genotypes. Beyond the repressive mechanisms of PAs on HM uptake, the latter also boost the production of phytochelatins (PCs), which bind, transport, and sequester the metal ions into the vacuole (Pál et al., 2017); possibly because they contribute to GSH pool, which is the building block of PCs. Higher PAs behave as stronger chelators or amplify chelation mechanisms (Nahar et al., 2016). Furthermore, PAs can also block cation channels in the sequence, $\mathrm{Spm}^{4+}>\mathrm{Spm}^{3+}>\mathrm{Put}^{2+}$, hence, they succor the sequestration of surplus metal ions during stress (Liu et al., 2014).

To what extent the innate stress resistance mechanisms of the host are persuaded by mycorrhizal symbiosis still remains ambiguous. Although mycorrhizal mediation of metallothionein $(M T), P C$ and HM tolerance (HMT) genes under HM stress have been unequivocally established, the "buffer effect" of AMF in improving the HM resistance of AM plants by orchestrating the PA metabolism has been very modestly studied and reported. Parádi (2003) studied the influence of Glomus intraradices on free PA content and ratios in Cd-exposed Daucus carota L. plants. AM plants did not register any significant change in the PA ratio unlike non-AM counterparts that showed reduced Spd and Put content. This could be due to the "equalizing effect" of AMF upon $\mathrm{Cd}$ exposure against the alteration in PA titers widely reported in various stress conditions. In poplar plants (clone AL35) grown in $\mathrm{Cu}$ and $\mathrm{Zn}$ polluted soil, inoculation with G. mosseae (Gm) and G. intraradices (Gi) provoked an overall increment in free and conjugated PAs by the induction of PaSPDS2 and PaADC expression (Cicatelli et al., 2010, 2014). Contrary to the first sampling stage (S1), PaADC expression was downregulated at second sampling stage (S2) in mycorrhizal plants under stress. In the presence of metal stress, both PaSPDS1 and PaSPDS2 were upregulated in Gi-inoculated poplar plants. At S2, both SPDS transcripts were induced by the inoculation with AMF 
on both non-stressed and stressed soil. At S1, on non-polluted soil, free PA levels were strongly reduced in the presence of AMF, while those of conjugated PAs were significantly higher in AM plants. On polluted soil, free Spd titers were significantly higher in the presence of AMF, especially Gi; conjugated Spd and Spm titers were also dramatically enhanced (up to 5-fold) relative to uninoculated controls, but only in $G i$-inoculated plants (Cicatelli et al., 2010, 2014). Amelioration of lead (Pb) toxicity in mycorrhized Calopogonium mucunoides was related to the alteration in amino acid profile, deviating metabolic flux toward PA synthesis from protein synthesis (Souza et al., 2014) (Table 1). Taken together, these results advocate that stress amelioration is driven from AMF-mediated regulation of these protective molecules under the combined effect of toxic metals and AMF.

Research on AMF-regulated PA metabolism and function during metal stress is in its infancy; hence, countless efforts are required to unravel the molecular dialog of AMF and PA and their protective role in HM stress tolerance. Employment of "-omics" approaches is needed to amplify AMF-mediated PA actions toward HM toxicity. Also, the effect of co-inoculation of AMF with growth-promoting bacteria in reversing metal toxicity should be subjected to thorough scrutiny to fathom the potential of synergistic interactions of plant-associated microbes in the mediation of crop abiotic stress tolerance.

\section{Impact of Polyamines on Mycorrhizal Colonization}

The extent of mycorrhizal colonization, spore germination, and hyphal growth and propagation are also affected by various stressors (Wu et al., 2010; Shekoofeh et al., 2012). In that respect, PAs have been reported to, in turn, enhance the AM symbiosis by actively participating in signaling episodes of plant-fungus interaction (El Ghachtouli et al., 1995). This positive correlation between mycorrhizal colonization and PAs is validated by several studies. Based on their type and method of administration (soil drench or foliar application), PAs exerted their effectiveness on mycorrhizal ( $G$. intraradices) development and concomitantly improved the quantity and quality of corm, and enhanced flower parameters in Freesia hybrida (Rezvanypour et al., 2015). The application of PAs in grape plants yielded beneficial effects on the infection rate, spore number, and hyphal growth of Gigaspora margarita, which are significantly reduced by the application of a PA biosynthetic inhibitor, methylglyoxal bis-guanylhydrazone (Yong et al., 2003). These results have made the stimulatory effects of PAs on the symbiotic efficiency of AMF manifestable and apparently directed toward the role of PAs as potential "regulatory factors" in the mycorrhizal association. Wu et al. (2012b) reported that 14 weeks of exogenous PA application on C. tangerine inoculated with Paraglomus occultum resulted in accelerated mycorrhizal colonization, a greater number of infectious propagules (vesicles and arbuscules), an enhanced mycorrhizal status, and a higher root glucose concentration, suggesting that PAs probably facilitate the transformation of root sucrose to glucose (usable form of carbohydrate for the fungus) to promote mycorrhizal proliferation and development. The PAmediated stimulation of root colonization can be attributed to various reasons: (1) PAs directly interact with fungal pectinases and boost adhesion, fungal penetration, and growth into the cell wall of plants (Nogales et al., 2009), (2) PAs reduce the ethylene levels in roots, which otherwise inhibit root colonization (Foo et al., 2016; Mattoo and White, 2018), and (3) AMF proliferation and development begins with chromatin decondensation of the host nucleus, corresponding to higher transcriptional activity (Berta et al., 1990), essential to which are PAs as they stabilize RNA against RNase activity (Serafini-Fracassini et al., 1984). Thus, PAs function as regulatory molecules in plant-AMF interactions (El Ghachtouli et al., 1995) (Figure 3).

\section{AQUAPORINS: TYPES AND BACKGROUND}

One of the crucial parameters that govern the development and stages of growth in plants is the stringent regulation of transcellular water movement, conduction, and mobilization. Diffusion of water across cells is facilitated by AQPs, the members of major intrinsic proteins (MIPs) family, that serve as a nexus between and within the cells, passively conducting water, gases, and solutes. Multiple isoforms of AQPs are found in plants, the fact that is reflective of a high degree of compartmentalization of cells, selectivity and size specificity of transport, and regulation properties that fine-tune water transport (Kapilan et al., 2018). As per the amino acid sequence homology, MIPs can be categorized into four major subgroups: (1) plasma membrane intrinsic proteins (PIPs) constitute the largest subfamily of MIPs and sit predominantly in the plasma membrane of the cells localized in the plant organs marked by high water fluxes, such as guard cells and root cells; (2) tonoplast intrinsic proteins (TIPs) chiefly reside in the vacuolar membrane serving as conduits for the transportation of water, small solutes, metabolites, and gases, thereby contributing to rapid osmotic homeostasis of the cytosol and maintenance of the cellular hydrostatic pressure; (3) nodulin-26 like intrinsic proteins (NIPs) are the aqua-glyceroporins found localized in the peribacterial membranes of the root nodules, hence being supposed to be presumably involved in the exchange of metabolites (glycerol and water, chiefly) betwixt the host plant and the $\mathrm{N}_{2}$-fixing bacterial symbionts; and (4) small basic intrinsic proteins (SIPs) are localized in the membrane of endoplasmic reticulum (ER); however, their precise physiological functionality is indeterminate (Ishikawa et al., 2005).

Expression and activity of AQPs are regulated by several processes, such as gating, which deals with the phosphorylation and dephosphorylation of AQPs, heterotetramerization, divalent cations, hormones, and even ROS generated during abiotic stresses (Kapilan et al., 2018). Tight regulation of these molecular gears can enable efficient regulation of water conduction under stress. Owing to the isoform multiplicity of AQPs and distinct expression patterns under stress (it may reduce, increase, or may remain unchanged), the discrete and integrated functionality of AQPs under diverse physiological conditions under stress remains elusive. The regulation of water conduction by AQPs under a variety of abiotic stresses depends on multiple parameters: the nature, duration and intensity of stress, 
conditions of plant growth, developmental stage, the type of tissue expressing AQP genes, and the type/isoform of AQP being expressed (Siemens and Zwiazek, 2004). There is a considerable dearth of such studies in the literature that directly integrate the relationship among the two biomolecules (PA and AQP) and AMF per se. However, it can be speculated that PA homeostasis has some roles to play in regulating the distribution and abundance of AQP proteins by virtue of which plant-water relations are maintained (Tailor and Bhatla, 2021). The authors studied the effect of potent PA inhibitors (DFMA and DFMO) on the expression of two major AQP families: PIP2 and TIP1 in saltstressed Helianthus annuus L. seedlings. The seedling that was raised in $500 \mu \mathrm{M}$ of DFMO and DFMA exhibited a significant root extension, irrespective of the salt-stressed imposed, and resulted in further exacerbating the decrease in relative water content (RWC) in roots and cotyledons. This was found to be correlated with augmented levels of PIP2 and TIP1 proteins in the roots but not in the cotyledons, of the seedling (Tailor and Bhatla, 2021). This arena of study integrated with the role of AMF colonization in further modulating the two biomolecules can offer a good research question to investigate. On this account, it can be deduced, a priori, that AMF-regulated PA homeostasis that accounts for improved adaptation of plants to water-deficit conditions ( $\mathrm{Hu}$ and Chen, 2020; Hu et al., 2020; Zhang et al., 2020) could be correlated to an extent as a function of modulation of the abundance of AQP subfamilies. However, no direct correlation between PAs and AQPs has been established hitherto.

\section{AMF-MEDIATED REGULATION OF AQUAPORINS UNDER STRESS}

Complete establishment of AM symbiosis in plants needs extensive morphological and molecular reprogramming with most of the morphological alterations concerned with changes in membrane system of vacuole and cytoplasm. Since AM symbiosis potentially alters root hydraulic conductivity in plants, the fact that it regulates AQP gene expression and protein abundance seems more convincing. The first wave of an attempt to characterize AMF-mediated changes in the AQP profile rose by Roussel et al. (1997), who reported mycorrhiza-induced TIP expressions in Petroselinum crispum, followed by that of Krajinski et al. (2000), who conducted the experiment along similar lines in Medicago truncatula and completely credited the changes of $M t A Q P 1$ expression profile to AMF colonization. They proposed that mycorrhiza-induced heightened expression of MtTIP is crucial to optimize water conduction after the changes that commence in plants on symbiosis establishment. Arbusculecontaining root cortical cells may register an altered ratio of cytoplasmic content and vacuolar space, due to which, changes in the tonoplast may be required to buffer the osmotic instability in the cytoplasm. Higher MtTIP expression could offer a way of redressing the reduced tonoplast water permeability of the highly compartmented vacuoles in the cells harboring fungal symbionts. Analogously, Medicago plants inoculated with $G$. mosseae showed an apparently enhanced expression of MtPIP2;1 and MtNIP1 while transcript abundance of other isoforms were uninfluenced by mycorrhization (Uehlein et al., 2007) (Table 2). The peri-arbuscular membrane (PAM) surrounding the arbuscules is a site of transmembrane water and solute transport across the plant-fungus interface. The strong induction of AQP expression during mycorrhization might be indicative of the physiological alterations, i.e., the optimization of water and solute transport system in the roots (the site of plantfungus interaction), as symbiotic exchange occurs through AQPs localized in the PAM. AQPs furnish a very low-resistance transcellular water conduction pathway through the membrane, which seems to be predominantly managed by TIPs and PIPs that are the central regulators of the conduction pathway (Maurel, 2007). Many AMF-regulated AQPs conduct solutes such as glycerol, urea, and $\mathrm{H}_{2} \mathrm{O}_{2}$ along with water, all of which are vital to the physiological performance of plants (Bárzana et al., 2014). Apart from these roles, AQPs also exert a potential influence on redox events in plants under unfavorable conditions. Additionally, since AQPs can be gated through reversible phosphorylation and dephosphorylation, this offers a way to control the water fluxes and movement dynamics across the cellular and vacuolar membranes.

\section{Salt Stress}

The strategic effect of mycorrhization on water acquisition and transport in salt-stressed and non-stressed plants strongly suggests its impact on AQP channels that mediate water transport in plants (Chen et al., 2017). The expression profile of AQPs in mycorrhizal plants experiencing salinity stress has revealed strikingly different results in different studies. Ouziad et al. (2006) reported that the transcript levels of LePIP1 and LeTIP exhibited a significant reduction in the roots and a slight upregulation in the leaves of the salt-stressed tomato colonized with Glomus spp. The tissue-specific expression suggests that fungi might acquire the function of water mobilization and transportation from roots to shoots, rather than the water uptake by roots from the soil, as the latter would allow the ingression of toxic $\mathrm{Na}^{+}$and $\mathrm{Cl}^{-}$ions into the roots along with the inflow of water; as few AQPs are reported to have $\mathrm{Na}^{+}$conduction properties, like AtPIP2;1 and AtPIP2;2 of Arabidopsis (Kourghi et al., 2017). In another study, the transcript levels of LsPIP1 and LsPIP2 were inhibited by mycorrhization ( $G$. intraradices) in non-stressed Lactuca sativa plants; however, the expression of LsPIP1 got enhanced with $100 \mathrm{mM}$ high-salinity $\mathrm{NaCl}$ dose, while no stark difference in that of LsPIP2 was notable between AM and non-AM plants (Jahromi et al., 2008).

The dynamism of AQP responses depends on the strain of AMF and the host type, the intrinsic nature and mode of the osmotic stress applied, and the isoform of AQP, adding layers of complexity to the AMF-mediated regulation of AQP expression (Jahromi et al., 2008; Ruiz-Lozano and Aroca, 2010). Four PIP genes analyzed in Phaseolus vulgaris plants colonized with $G$. intraradices, and subjected to salinity, low temperature, or drought stress, revealed contrasting results (Aroca et al., 2007). Three of the genes investigated exhibited differential regulation by mycorrhization under each stress regime. Salinity stress resulted in the upregulation of all the PIP genes in both sets of plants (AM and non-AM), with a considerable enhancement in 
TABLE 2 | Summary of studies on effects of AM symbiosis on aquaporin (AQP) gene expression under non-stressed, water-deficit (salt and drought stress), and heavy metal (HM) stress conditions. The consequences of AMF-mediated AQP regulation on physiology of stressed plants are also included.

\begin{tabular}{|c|c|c|c|c|c|}
\hline $\begin{array}{l}\text { Abiotic } \\
\text { conditions }\end{array}$ & $\begin{array}{l}\text { Plant } \\
\text { species }\end{array}$ & AMF Species & $\begin{array}{l}\text { AMF-mediated effects on Aquaporin } \\
\text { gene expression }\end{array}$ & $\begin{array}{l}\text { Consequences on physiology of } \\
\text { AM Plants }\end{array}$ & References \\
\hline \multirow[t]{4}{*}{ No Stress } & $\begin{array}{l}\text { Petroselinum } \\
\text { crispum }\end{array}$ & $\begin{array}{l}\text { Glomus } \\
\text { fasciculatum }\end{array}$ & $\uparrow P C T I P$ & Plant water status not measured & Roussel et al., 1997 \\
\hline & $\begin{array}{l}\text { Medicago } \\
\text { truncatula }\end{array}$ & G. mosseae & $\uparrow M t T I P$ & Plant water status not studied & Krajinski et al., 2000 \\
\hline & $\begin{array}{l}\text { Poplar tremula } \times \\
\text { tremuloides }\end{array}$ & G. mosseae & 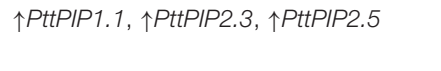 & Increased $L_{0}$ in AM plants & Marjanović et al., 2005 \\
\hline & $\begin{array}{l}\text { Medicago } \\
\text { truncatula }\end{array}$ & Unpublished data & $\uparrow M t P I P 2 ; 1$ and $\uparrow M t N I P 1$ & $\begin{array}{l}\text { Plant water status not taken into } \\
\text { account }\end{array}$ & Uehlein et al., 2007 \\
\hline \multirow[t]{6}{*}{ Salt stress } & $\begin{array}{l}\text { Lycopersicum } \\
\text { esculentum }\end{array}$ & $\begin{array}{l}\text { G. geosporum and } \\
\text { G. intraradices }\end{array}$ & $\begin{array}{l}\downarrow \text { LePIP1 and } \downarrow \text { LeTIP } \\
=\text { LePIP2 }\end{array}$ & $\begin{array}{l}\text { Plant water status analysis not } \\
\text { conducted }\end{array}$ & Ouziad et al., 2006 \\
\hline & $\begin{array}{l}\text { Phaseolus } \\
\text { vulgaris }\end{array}$ & G. intraradices & $\begin{array}{l}\uparrow P \vee P I P 1.1,=P \vee P I P 1.3 \\
\uparrow P \vee P I P 2.1, \downarrow P V P I P 1 ; 2\end{array}$ & Increase in $J_{v}, L_{0}$, and RWC & Aroca et al., 2007 \\
\hline & Lactuca sativa & G. intraradices & $\uparrow L s P I P 1$ and $=L s P I P 2$ & $\begin{array}{l}\text { Increased RWC, lower ABA } \\
\text { accumulation in roots, lower proline } \\
\text { content }\end{array}$ & Jahromi et al., 2008 \\
\hline & $\begin{array}{l}\text { Robinia } \\
\text { pseudoacacia }\end{array}$ & $\begin{array}{l}\text { Rhizophagus } \\
\text { irregularis }\end{array}$ & $\begin{array}{l}\text { Roots: } \uparrow R p P I P 1 ; 3, \uparrow R p P I P 2 ; 1, \\
\uparrow R p T I P 1 ; 1 \downarrow R p T I P 1 ; 3 \\
\text { Leaves: } \downarrow R p P I P 2 ; 1 \text { and } \downarrow R p T I P 1 ; 3 \\
\uparrow R p P I P 1 ; 1 \text { and } \uparrow R p P I P 1 ; 3\end{array}$ & $\begin{array}{l}\text { Increase in the RWC at } 200 \mathrm{mM} \mathrm{NaCl} \\
\text { by } 9 \% . \text { increased WST, improved Pn } \\
\text { by } 106 \% \text { at } 100 \mathrm{mM} \mathrm{NaCl} \text { and by } \\
81 \% \text { at } 200 \mathrm{mM} \mathrm{NaCl} \text {, Higher WUE, } \\
\text { Lower Ci, higher Gs than non-AM } \\
\text { plants }\end{array}$ & Chen et al., 2017 \\
\hline & Poncirus trifoliata & $\begin{array}{l}\text { Paraglomus } \\
\text { occultum }\end{array}$ & $\begin{array}{l}\downarrow P t T I P 1 ; 1, \downarrow P t T I P 1 ; 2 \text { and } \downarrow P t T I P 1 ; 3 \\
=\text { PtTIP2;1, =PtTIP2;2 } \uparrow \uparrow P t T I P 4 ; 1 \\
\text { (no salt) }\end{array}$ & $\begin{array}{l}\text { Spurred root water absorption, } \\
\text { accelerated }\end{array}$ & Ding et al., 2020 \\
\hline & Lactuca sativa & $\begin{array}{l}\text { F. mosseae and } \\
\text { Claroideoglomus } \\
\text { lamellosum }\end{array}$ & $\begin{array}{l}\uparrow \uparrow P t T I P 5 ; 1 \text { (salt stress) No effect on } \\
\text { PIP1, } \uparrow P I P 2 \text { ( } \uparrow \text { PIP2A, } \uparrow P I P 2 B \\
\uparrow P I P 2 C \text { ) abundance }\end{array}$ & $\begin{array}{l}\text { Leaf } \Psi \text { by } 9.14 \% \text {, significantly higher } \\
\text { RWC }\end{array}$ & Santander et al., 2021 \\
\hline \multirow[t]{13}{*}{$\begin{array}{l}\text { Drought } \\
\text { stress }\end{array}$} & $\begin{array}{l}\text { Glycine max, } \\
\text { Lactuca } \\
\text { sativa }\end{array}$ & R. intraradices & $\begin{array}{l}\downarrow G m P I P 1, \downarrow G m P I P 2 \\
\downarrow L s P I P 1, \downarrow \text { LSPIP2 }\end{array}$ & Higher leaf $\Psi$ and RWC & Porcel et al., 2006 \\
\hline & $\begin{array}{l}\text { Phaseolus } \\
\text { vulgaris }\end{array}$ & G. mosseae & $\begin{array}{l}\downarrow P V P I P 1 ; 1, \downarrow P V P I P 1 ; 2, \downarrow P V P I P 1 ; 3 \\
\downarrow P V P I P 2 ; 1\end{array}$ & Increased RWC and $J_{v}$ & Aroca et al., 2007 \\
\hline & Zea mays & $\begin{array}{l}\text { R. intraradices } \\
\text { Isolate BEG } 121\end{array}$ & $\begin{array}{l}\uparrow Z m P I P 1 ; 1, \uparrow Z m P I P 1 ; 2 \uparrow Z m P I P 2 ; 5, \\
\uparrow Z m P I P 2 ; 6 \downarrow Z m P I P 2 ; 2\end{array}$ & $\begin{array}{l}\text { Application of exogenous } \\
\text { ABA enhanced } J_{V} \text { and } L_{\circ} \text { in } \\
\text { AM and non-AM plants, regardless of } \\
\text { the water regime }\end{array}$ & $\begin{array}{l}\text { Ruiz-Lozano et al., } \\
2009\end{array}$ \\
\hline & Z. mays & R. intraradices & Short term drought: & Increased $J_{v}$ and $L_{o}$ values & Bárzana et al., 2014 \\
\hline & & & $\uparrow Z m P I P 1 ; 1, \uparrow Z m P I P 1 ; 2$ & Increased Lh values under & \\
\hline & & & $\uparrow Z m P I P 1 ; 3, \uparrow Z m P I P 1 ; 4$ & drought & \\
\hline & & & $\uparrow Z m P I P 1 ; 6, \uparrow Z m P I P 2 ; 2$ & & \\
\hline & & & $\uparrow Z m P I P 2 ; 4, \uparrow Z m P I P 1 ; 1$ & & \\
\hline & & & $\uparrow Z m P I P 1 ; 2$ & & \\
\hline & & & $\uparrow Z m T I P 1 ; 1, \uparrow Z m T I P 1 ; 2$ & & \\
\hline & & & $\downarrow Z m N I P 2 ; 1, \downarrow Z m N I P 2 ; 2$ & & \\
\hline & & & 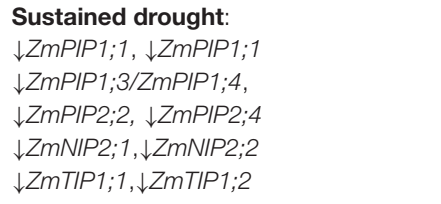 & $\begin{array}{l}\text { Decreased } J_{v} \text { and } L_{0} \text { values, reduced } \\
\text { sap flow, decreased Si uptake, } \\
\text { decreased B uptake, enhanced } \\
\text { RLWC, Leaf } \Psi \text {, and ABA level in roots } \\
\text { and better plant growth performance }\end{array}$ & \\
\hline & $\begin{array}{l}\text { Robinia } \\
\text { pseudoacacia }\end{array}$ & R. irregularis & $\begin{array}{l}\text { Roots: } \downarrow R p T I P 1 ; 1 \downarrow R p P I P 1 ; 3 \\
\text { Stem: } \uparrow R p T I P 1 ; 1, \uparrow R p T I P 2 ; 1, \\
\uparrow R p P I P 2 ; 1, \downarrow R p P I P 1 ; 1, \downarrow R p P I P 1 ; 3 \\
\text { Leaves: } \uparrow R p T I P 2 ; 1, \uparrow R p P I P 2 ; 1 \\
\downarrow R p T I P 1 ; 3, \downarrow R p P I P 1 ; 3\end{array}$ & $\begin{array}{l}\text { Higher dry mass and lower WSD and } \\
\text { electrolyte leakage, increased leaf Pn } \\
\text { and Gs }\end{array}$ & He et al., 2016 \\
\hline
\end{tabular}


TABLE 2 | Continued

\begin{tabular}{|c|c|c|c|c|c|}
\hline $\begin{array}{l}\text { Abiotic } \\
\text { conditions }\end{array}$ & $\begin{array}{l}\text { Plant } \\
\text { species }\end{array}$ & AMF Species & $\begin{array}{l}\text { AMF-mediated effects on Aquaporin } \\
\text { gene expression }\end{array}$ & $\begin{array}{l}\text { Consequences on physiology of } \\
\text { AM Plants }\end{array}$ & References \\
\hline & $\begin{array}{l}\text { Poncirus } \\
\text { trifoliata }\end{array}$ & G. mosseae & $\begin{array}{l}\uparrow P \text { PTIP1;2, } \uparrow \text { PtTIP1;3, } \uparrow \text { PtTIP4;1 } \\
\downarrow \text { PtTIP2;1 and } \downarrow \text { PtTIP5; } 1 ; \text { PtTIP1;1 and } \\
\text { PtTIP2;2 unaffected }\end{array}$ & $\begin{array}{l}\text { Significantly enhanced leaf RWC, Leaf } \\
\Psi \text {, and plant growth performance } \\
\text { (plant height, stem diameter, leaf } \\
\text { number, and biomass), elevated root } \\
\text { ABA levels }\end{array}$ & Jia-Dong et al., 2019 \\
\hline & Z. mays & R. irregularis & $\uparrow Z m P I P 2 ; 1, \uparrow Z m P I P 2 ; 6$ & $\begin{array}{l}\text { Enhanced } \mathrm{Pn}, \mathrm{gs}, \mathrm{Ci} \text {, and water } \\
\text { permeability of mycorrhizal plants }\end{array}$ & Quiroga et al., 2019a \\
\hline & Z. mays & F. mosseae & $\begin{array}{l}\downarrow P t P I P s, \text { unaltered PtTIPs, } \downarrow \downarrow \text { PtNIP1; } 1, \\
\downarrow \downarrow P t N I P 5 ; 1, \downarrow \downarrow P t N I P 6 ; 1\end{array}$ & $\begin{array}{l}\text { Enhanced Pn, gs, E, leaf } \Psi \text {, and } \\
\text { RWC; lower Lt. Increased plant } \\
\text { growth performance of AM plants }\end{array}$ & Zou et al., 2019 \\
\hline $\begin{array}{l}\text { Heavy Metal } \\
\text { Stress (low, } \\
\text { moderate and } \\
\text { high Cu stress) }\end{array}$ & $\begin{array}{l}\text { Salix } \\
\text { purpurea L. }\end{array}$ & R. irregularis & $\begin{array}{l}\text { TIP2;2 in roots of inoculated plants, } \\
\uparrow P I P 1 ; 2 \text { in low-Cu treatment samplings, } \\
\text { PIP2;2 steady among all Cu-treatments }\end{array}$ & $\begin{array}{l}\text { Increased } \mathrm{L}_{0}, \text { moderated } \\
\mathrm{K}_{\mathrm{L}} \text {, increased antioxidant } \\
\text { capacity ( } \uparrow \mathrm{SOD} \text { and } \uparrow A P X)\end{array}$ & $\begin{array}{l}\text { Almeida-Rodríguez } \\
\text { et al., } 2016\end{array}$ \\
\hline
\end{tabular}

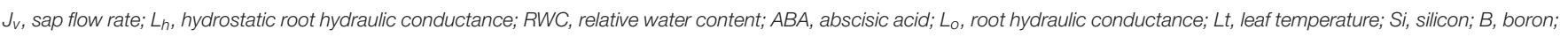

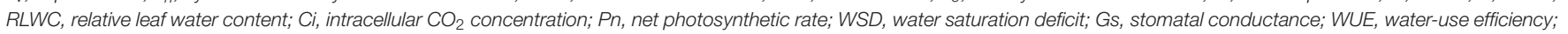
$\Psi$, water potential; $S O D$, superoxide dismutase; $A P X$, ascorbate peroxidase; $K_{L}$, leaf-specific conductivity.

AM plants (Table 2). Such a kind of differential AQP expression registered under each stress based on the presence of AMF may be indicative of the following: (1) difference at the level of regulation under the specified set of stresses, (2) different functions performed by each PIP isoform analyzed under each stress examined, and (3) substitution/compensation of the roles performed by plant AQPs by that of fungal AQPs depending on the particular stress foisted. However, to confirm the latter hypothesis, a simultaneous expression profile of fungal AQPs under different stress episodes needs to be generated.

Chen et al. (2017) detected an upregulation of four AQP genes, RpPIP1;1, RpPIP1;3, RpPIP2;1, and RpTIP2;1, in all the mycorrhizal Robinia pseudoacacia plants at high-salinity dosage $(200 \mathrm{mM}$ of $\mathrm{NaCl})$. In this experiment, $\mathrm{AM}$ plants were found to exhibit lower values of intracellular (carbon dioxide) $\mathrm{CO}_{2}$ concentration $(\mathrm{Ci})$ under all doses of salinity. Higher $\mathrm{Ci}$ value reflects demolition of the photosynthetic apparatus and passivation of enzymes involved in $\mathrm{CO}_{2}$ fixation that results in reduced $\mathrm{CO}_{2}$ assimilation (Sheng et al., 2008). Besides, AM plants also experienced less reduction in Gs (stomatal conductance) values under salinity, which indicated better water status of mycorrhized plants, enabled by "maintained" $\mathrm{CO}_{2}$ diffusion through stomata by the regulation of leaf AQPs. Likewise, in another recent study on $P$. trifoliata, inoculation with $P$. occultum resulted in differential expression of TIP isoforms and spurred water absorption ( $\uparrow$ RWC) and accelerated the leaf $\Psi$ (water potential) by $9.14 \%$ (Ding et al., 2020). In L. sativa [two cultivars, Grand Rapids (GR) and Lollo Bionda (LB)] inoculated with a consortium of F. mosseae and Claroideoglomus lamellosum, no alteration in PIP1 abundance was observed, which the authors attribute to the conservative nature of these proteins. In salt-stressed AM cultivars, increased phosphorylation levels of PIP2A, PIP2B, and PIP2C were observed compared to the non-inoculated counterparts. Also, an increased level of PIP2 proteins was observed in the membrane of inoculated GR plants as opposed to non-inoculated ones subjected to salt stress (Santander et al., 2021) (Table 2). All the studies analyzed, hitherto, are congruent with the findings of Valot et al. (2005) that the inoculation of a plant (M. truncatula) with mycorrhiza $(G$. intraradices) differentially regulates several plasma membrane proteins, some of them are inhibited while some of them are induced.

There are currently two schools of thought that explain the diverse expression of AQPs registered in response to AMF under desiccation stress. The first one is premised on the induced expression of AQPs under dehydration stress, which is plausibly explained as a mechanism to boost membrane permeability and facilitate the water uptake and conduction in planta. The second is premised on the fact that the expression of AQPs is inhibited in plants experiencing dehydration stress; this might be an efficient strategy to facilitate water conservation by decreasing membrane permeability to water as well an endeavor of the plant to conserve metabolic energy under stressful conditions (Sonah et al., 2017).

\section{Drought Stress}

Since AQPs are inherently regulated at transcriptional and posttranscriptional levels, it becomes important to delineate the exact role of AMF in the modulation of AQP-encoding genes as a mechanism to enhance the stress tolerance of plants under water-deficit conditions. However, the dynamics of AMF-mediated AQP regulation remain enigmatic to date. Abiotic stress, mycorrhization, or an interplay between the both evokes a signaling relay that begins with the generation of stress messengers and/or stress-induced hormones. We posit that AMF, under stress, might influence the AQP expression at transcriptional, translational, and post-transcriptional (phosphorylation, multimerization, cycling, and internalization of AQPs) levels that contributes to the overall increment in AQP expression and protein abundance, thus boosting the conduction of $\mathrm{H}_{2} \mathrm{O}, \mathrm{CO}_{2}$, glycerol, $\mathrm{NH}_{3}$, etc., in stressed plants. AMF-reinforced regulation of AQP expression and transcript abundance can fortify tolerance of plants to water-deficit conditions arising from different stresses by improving root 


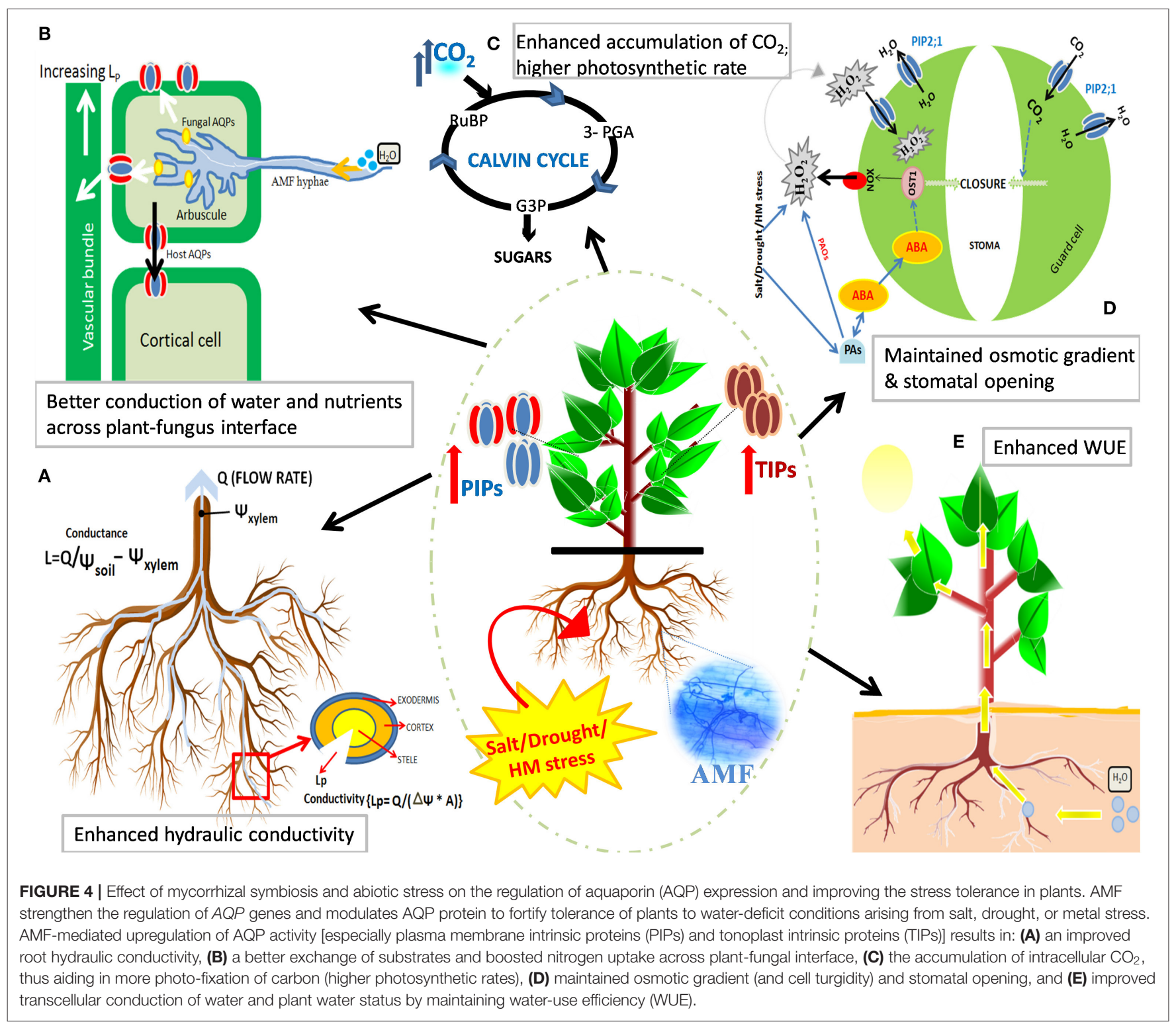

hydraulic conductivity, better exchange of nutrients across the plant-fungus interface, higher photosynthetic rates, maintaining cell turgidity and stomatal opening, and improving water-use efficiency of the plant (Figure 4).

As proposed by Javot and Maurel (2002), the ability of AMF to accelerate the water uptake in roots should imply enhanced permeability of water, which can be derived from higher activity of AQP genes; which is why mycorrhization should account for the upregulation of AQPs to promote transcellular water conduction. However, the results obtained in mycorrhized water-stressed soybean and lettuce plants were incongruous to the aforementioned hypothesis, as PIP expression was downregulated in both the plants colonized by mycorrhiza (Glomus spp.), although the leaf $\Psi$ and RWC were higher in AM plants than their non-AM counterparts (Porcel et al., 2006). Such an effect of AM symbiosis might be conceived as a regulatory mechanism operative in AM plants to: (1) conserve metabolic energy under stressful conditions or (2) restrict water loss from the tissues into the hypertonic soil milieu. However, the downregulation of PIP genes was observed only in the case of plants inoculated with $G$. mosseae and not with $G$. intraradices. The results, somehow, correspond with the study of Marulanda et al. (2003), wherein the soil-water uptake capacity of $G$. intraradices was the highest and G. mosseae showed reduced efficiency thereof. This speaks for different strategies employed by the two fungi in order to safeguard plants from water stress. $G$. intraradices might be conditioned to enhance water permeability of roots and, thus, maintain higher expression of PIP aquaporins in the inoculated plants; while G. mosseae seems to be directing the conservation of already absorbed water in the plants, hence decreasing membrane water permeability by downregulating PIP gene expression (Ruiz-Lozano and Aroca, 2010). 
In another study conducted by Porcel et al. (2005), the symbiotic efficiency (measured in terms of plant biomass), and not the root colonization efficiency, of the mycorrhized NtAQP1 antisense tobacco plants was compromised on silencing the NtAQP1 gene under drought stress. The results obtained have led to suggest the following: (1) NtAQP1 is irrelevant in the colonization process, (2) the reduction in NtAQP1 transcripts might have been compensated by other AQPs, and/or (3) NtAQP1 is involved in $\mathrm{CO}_{2}$ diffusion in tobacco accounting to the promotion of photosynthesis and augmented production of photosynthates, resulting in better growth of plants (Uehlein et al., 2003; Bárzana et al., 2012). Symbiosis by Rhizophagus irregularis enhanced drought tolerance in $R$. pseudoacacia plants by calibrating the expression of $R p A Q P$ genes, and by improving plant biomass, cellular water status, net photosynthetic rate, and stomatal conductance (He et al., 2016). The expression levels of RpTIP2; 1 and RpPIP2; 1 were consistently augmented by AMF in all three tissues, leaves, stem, and roots during stress, thereby canalizing water fluxes toward plant tissues of significant importance in physiology. Differential expression of AQPs has also been reported in AMF-inoculated Zea mays (Bárzana et al., 2014) and P. trifoliata (Jia-Dong et al., 2019), manifested in altered physiology and plant growth performance under different regimes of drought stress (Table 2). Changes in the AQP gene expression profile under drought stress has been noticed not only in plants associated with AMF but also in the colonizing AM species thereof. The expression of two AQP genes, GintAQPF1 and GintAQPF2, of G. intraradices, was significantly induced in response to water-deficit conditions, thus reinforcing the postulation of AMF involvement in directing plant tolerance to cellular desiccation by increasing water-use efficiency (WUE) (Li et al., 2013).

In maize colonized by $R$. intraradices, $Z m P I P 2 ; 2$ and $Z m P I P 2 ; 6$ were induced by the AMF along with the induced expression of fungal GintAQPF2 under drought stress. AM inoculation resulted in an increased photosynthetic rate, an enhanced stomatal conductance, and a higher photosynthetic capacity. The phosphorylation levels of PIP2 were also found to be enhanced that might have translated into increased AQP activities in the mycorrhizal plants (Quiroga et al., 2019a). In mycorrhizal maize plants, the abundance of phosphorylated AQP proteins (PIP1, PIP2, PIP2A, PIP2B, and PIP2C) decreased in well-watered plants subjected to IAA or 6FI (inhibitor of IAA). However, not so significant changes were observed in the phosphorylation levels of AQPs in drought-stressed mycorrhizal plants (Quiroga et al., 2020) (Table 2). Similar observations were obtained in a previous study by Quiroga et al. (2019b), wherein no change in $Z m A Q P$ accumulation was observed in droughtstressed AM plants in the presence of sodium azide (metabolic inhibitor of AQPs). This could be attributed to the already higher apoplastic water flow and root hydraulic conductance in AM plants (over non-AM plants). Thus, the inhibitory effect of sodium azide on root hydraulic conductance in AM plants was lesser, which, together with increased apoplastic water flow, suggested a compensatory mechanism for the inhibition of AQP activity in these plants under stress (Quiroga et al., 2019b). Even so, Zou et al. (2019) observed that the expression of all PtPIPs in drought-stressed trifoliate orange was downregulated by the AMF treatment, while the PtTIPs expression remained unaltered under the same set of conditions. Increased overexpression of PIPs may accelerate wilting in plants; hence the decreased PIP expression in AMF-inoculated drought-stressed plants can be speculated as a mechanism to minimize water loss in stressed plants (Ruiz-Lozano and Aroca, 2017). Besides, a dramatic reduction in the root PtNIP1;1; PtNIP5;1 and PtNIP6;1 levels were observed in water-stressed AM plants. As fungal hyphae can directly provide boron to the host plant, the decrease of NIPs is seen as a potential avoidance mechanism to the ensuing toxicity by otherwise excessive boron accumulation in the plant (Ruiz-Lozano and Aroca, 2017). In yet another study by Jia-Dong et al. (2019), both drought stress and AMF notably amplified the relative level of expression of root PtTIP1;2, PtTIP1;3, and PtTIP4; 1 in P. trifoliata, which might have accounted for an increased active water absorption. Contrastingly, the expression levels of PtTIP2;1 and PtTIP5;1 were found to be reduced in stressed AM plants. Since fungal hyphae can also meet the water needs of the host plant, this might be a strategy of AM plants to not rely on extensive host $\mathrm{AQP}$ expression and conserve energy. Moreover, increased ABA content observed in these plants could have hastened the water retention, thereby diminishing the requirement for overexpression of all the root-TIPs to absorb water (Table 2).

Taken together, it can be summarized that different AQP genes exhibit upregulation or downregulation under the same stress regime and those belonging to the same subgroup may register distinct expression profiles under different stress regimes (Bárzana et al., 2014). The expression pattern of same isoforms also differs with the fungal strain under study and the tissue analyzed. Despite vast experimental evidence about the implication of AQP genes in various stress responses, the explicit role of individual genes or specific AQP subfamilies is still baffling, owing to their extremely complex and integrated roles in response to various environmental stimuli, and active participation in fundamental growth and developmental processes. A comprehensive understanding of how AMF regulates $\mathrm{AQP}$ gene expression has pragmatic implications for crop improvement and management under stress.

\section{Heavy Metal Stress}

As aforestated, the regulation of AQPs is governed by various factors including abiotic conditions like HMs. Metal ions influence the AQP activity by binding to the sulfhydryl groups of the proteins, inducing conformational changes (gating), and thus declining their water conduction capacity (Agre et al., 1998). Metal stress also affects the plant water status by impairing root growth, influencing stomatal density, decreasing vessel and tracheid size, all of which result in deceleration of short-distance and long-distance water conduction (RucińskaSobkowiak, 2016).

The regulatory influence of $\mathrm{HMs}$ on AQP activity and expression has been validated in several plants, like $\mathrm{Hg}$ stressed Pisum sativum (Beaudette et al., 2007), Cu-stressed Mesembryanthemum crystallinum (Kholodova et al., 2011), arsenic [As (III)] exposed Brassica juncea (Srivastava et al., 
2013), $\mathrm{HMs}\left(\mathrm{Zn}^{2+}, \mathrm{Pb}^{2+}, \mathrm{Cd}^{2+}\right.$, and $\left.\mathrm{Hg}^{2+}\right)$ stressed Allium cepa that accounted to metal-induced drop in water permeability in the order of $\mathrm{Hg}^{2+}>\mathrm{Cd}^{2+}>\mathrm{Pb}^{2+}>\mathrm{Zn}^{2+}$ (PrzedpelskaWasowicz and Wierzbicka, 2011), Zn-stressed poplar (Ariani et al., 2019), and Brassica rapa (Fatemi et al., 2020). Multiple reports validate the significance of AQP activity as efflux transporters that excrete HMs out of the cellular space (Vats et al., 2021). For instance, Oryza sativa NIP2;1 mediates As(III) efflux (Zhao et al., 2010), and NIPs from Arabidopsis participate in the expulsion of As (III) from the cell (Xu et al., 2015). Increased internalization and relocation of $\mathrm{AQP}$ proteins are also presumably associated with HM sequestration, and thus providing tolerance to the mechanism in plants (Vats et al., 2021). NIP2; 1 is a multifunctional AQP whose role in the transportation of As, B, and Si has been experimentally ratified (Yamaji and Ma, 2007; Ma et al., 2008; Schnurbusch et al., 2010). Grapevine $V v X I P 1$ is involved in the transportation of $\mathrm{Cu}, \mathrm{As}, \mathrm{Ni}$, along with $\mathrm{H}_{2} \mathrm{O}_{2}$, thus might have a prospective role in metal homeostasis and signaling (Noronha et al., 2016).

Aquaporin response is the primary feedback to metal toxicity; and disturbed water balance is the first stress-triggered episode affecting the AQP confirmation (open/closed) (PrzedpelskaWasowicz and Wierzbicka, 2011). This offers the notion that AQPs have a key role to render under metal stress. Nevertheless, the clear mechanistic role furnished by different $\mathrm{AQP}$ isoforms under stress is yet to be categorically established owing to the complexity of integrated stress response that further varies with the plant species (Vats et al., 2021). Hence, the modulation of this recondite player could be a potential mechanism reinforced by AMF under HM stress, like that under salinity and drought. Unfortunately, the studies that corroborate this hypothesis and clarify the relation between plant-water relation and metal stress, and conceived role of AMF-mediated modulation of AQP activity in this context are slim to none. An exclusive study on Salix purpurea L. (a potential phytoremediator of trace elements) was conducted by Almeida-Rodríguez et al. (2016) wherein the symbiotic association of the host plant and $R$. irregularis was found to regulate a wide spectrum of metabolic and physiological outcomes upon $\mathrm{Cu}$ exposure. AMFreinforced dynamic regulation of root AQPs, PIP1;2, together with an upregulation of root TIP2;2 were held accountable for the maintained root hydraulic conductivity $\left(\mathrm{L}_{\mathrm{P}}\right)$ and leaf-specific conductivity $\left(\mathrm{K}_{\mathrm{L}}\right)$ under $\mathrm{Cu}$ stress. The observed translocation and accumulation of $\mathrm{Cu}$ ions in the cell wall and different organelles might be an outcome of osmoregulation encouraged by AQPs. TIPs and PIPs are key conduits of water conduction during this process (Table 2).

Although there has been profuse knowledge explosion in the domain of plant-AMF-HM interaction and multiple mechanisms have been ascribed to the ameliorative role of mycorrhizal association in assuaging HM stress, the arena of AMF-regulated AQP expression under metal stress is least explored. Hence, this might offer a potential area of research to decode the bona fide contribution of AMF to AQP regulation under metal stress. Moreover, the studies that deal with the functional characterization of fungal $A Q P s$, which might serve as facultative AQPs to plants under stress, need to be performed.
How fungal AQPs get affected under HM stress remains unexplored. Research flux should be trained toward studying the effect of metal toxicity on both host and fungal AQP genes and whether fungal AQPs are competent to counterbalance the metalinduced AQP downregulation in the host plants. More fungal $\mathrm{AQP}$ genes need to be identified and examined for their structure, function, and regulation under stress and otherwise.

\section{CONCLUSION AND PERSPECTIVE FOR FUTURE STUDIES}

Recurring episodes of environmental stresses affect arable land and stifle plant growth at both quantitative and qualitative levels. As opposed to biotic stress, which is controlled by monogenic trait, tolerance to abiotic stress is a multigenic complex trait that involves a multi-component signaling cascade, hence more difficult to monitor and engineer comparatively. Lately, several efforts are being invested in refining metal/salt/drought tolerance through the AMF application (mycoremediation) or genetic engineering. However, the complexity of tolerance mechanisms and difficulty in the transfer of technology to field conditions account to apparent inconsistency between theory and practice.

As reiterated in the paper, there exists a synergism between AMF and PA metabolism, which is exploited in plants under stressful conditions. However, the properties of signaling mechanisms, intricacies of cross-talk between PAs and other metabolic routes, and an exact mechanism underlying the putative role of AMF in mediating PA-induced alleviation of abiotic stress are far from being completely decoded owing to the increasing level of complexity. Considering that, the transcriptomic and metabolomic investigation in plants with knocked out/down PA synthesizing and catabolizing genes, interacting with AMF under stress, could offer a good outset for research direction. Besides, these approaches can be extrapolated to legumes wherein "rhizobia-AMF-PA" tripartite interaction can be investigated (Menéndez et al., 2019). The effect of PA knockout mutants can also be studied on other metabolic routes that are in a close-knit association with the PA metabolism under stress.

The cellular and molecular mechanisms of mycorrhizal influence on the AQP expression profile (increase/decrease) in response to water-deficit conditions (imposed by salt, drought, and HM stress) remain elusive and need exhaustive research (Figure 5). These voids in understanding offer potential research landscapes in quest of deeper insights and practical implications of AMF in stress. In order to advance a step forward in understanding $\mathrm{AQP}$-abiotic stress relations in AM plants, the expression of the same AQP members (isoforms) should be investigated across different AMF species and types of stress in order to discern the specificity in $\mathrm{AQP}$ function and nature of regulation by AMF. Furthermore, probing the effect of the same AMF species on the AQP regulation across a combination of biotic and abiotic stresses could be another potential research line. Such studies can be conducted on multiple "HM/salt/drought-tolerant" AMF species that are naturally found in saline or metalliferous environments in association with 


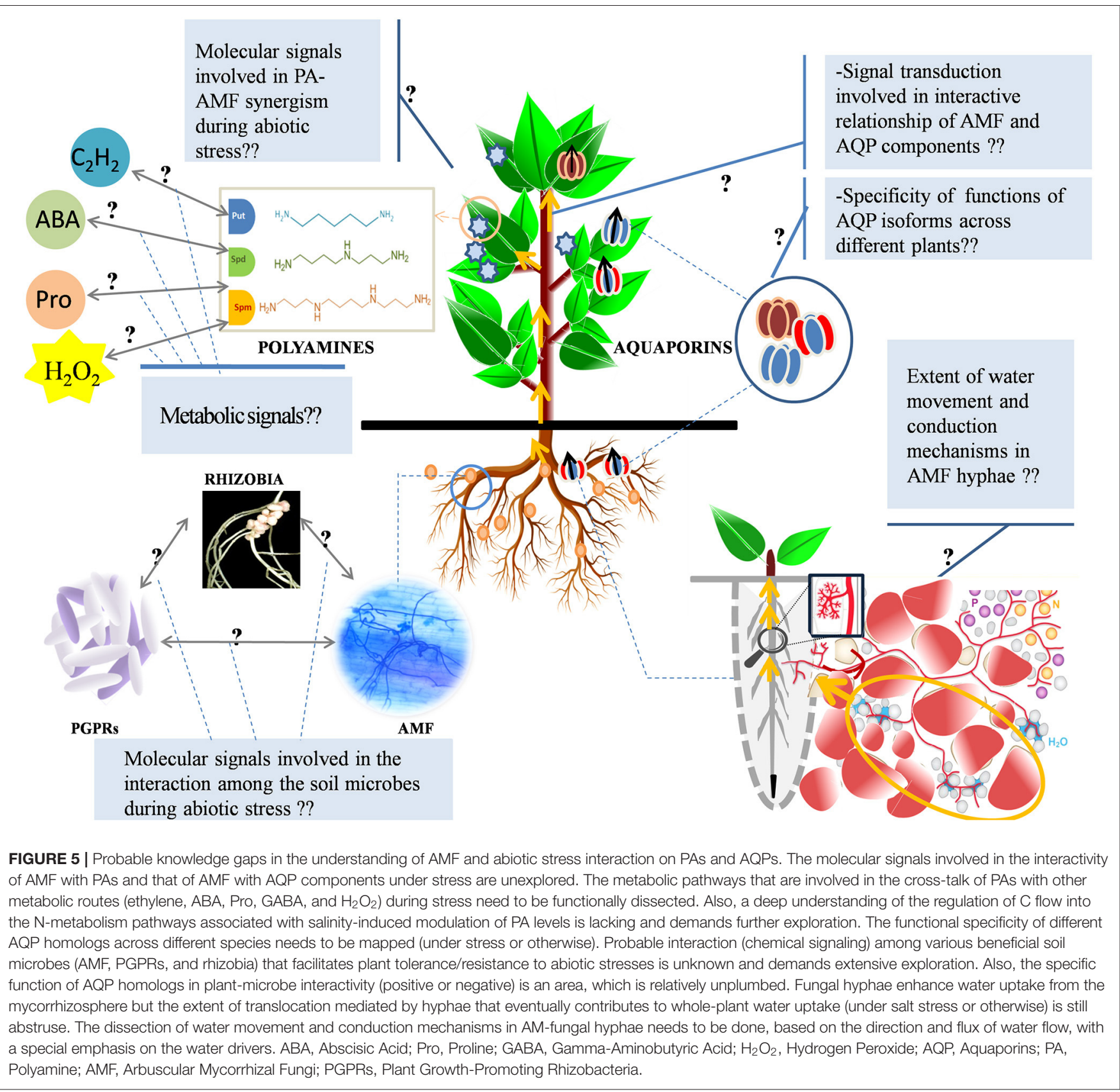

different crops, and then comparative analysis of their effects can be done in order to achieve the most efficacious combination of AMF species that can be employed as biofertilizers to dilute the ensuing toxic effects of stress on plants.

The fact that fungal hyphae enhance the water uptake from mycorrhizosphere to plant vasculature has been well-reviewed (Evelin et al., 2019), but the extent of translocation mediated by hyphae that eventually contributes to whole-plant water uptake (underwater deficit or otherwise) is still abstruse (Figure 5). On that account, the dissection of "water movement and conduction" mechanisms in AM-fungal hyphae needs to be done, based on the direction and flux of water flow with a special emphasis on the water drivers (AQPs, etc.) (Wu et al., 2013). Functional genomics can be integrated to expand the dimensions of our understanding on these facets. Identification of key mycorrhizal genes and TFs that contribute to the modulation of AQP activity should be identified, gauged, and engineered to improve crop health under stress and otherwise.

In plants, the stress-triggered damage can be attenuated by exploring and exploiting the potential of beneficial soil microbes [plant growth-promoting rhizobacteria (PGPRs), rhizobia, and $\mathrm{AMF}]$, and then employing them discretely or in combination. Numerous studies evince the positive influence of dual/triple inoculation on plant growth and tolerance under abiotic stress 
(Egamberdieva et al., 2013; Hashem et al., 2016; Hidri et al., 2019; Igiehon et al., 2020). Further research should focus on decoding the molecular signals that are involved in the interaction among the bio inoculants that ultimately influence plant physiology (Aroca and Ruiz-Lozano, 2009). The efficacy of multiple inoculations vs. single inoculation has also been investigated. Nonetheless, a lot more is there to understand about the fundamental mechanisms that are influenced by AMF and/or PGPR and/or rhizobia under stress (Yasmeen et al., 2019). A comprehensive molecular and physiological understanding of underlying mechanisms would enable us to better exploit the microbial bioresources as a potential tool for assuaging abiotic stress (Figure 5). Functional analysis of different growthpromoting microbes as first-generation plant biostimulants, when they are administered alone or in combination, would pave a way for the development of second-generation biostimulants with cooperative and complementary actions, mechanism of which can be functionally tailored. Besides, the employment of both microbial and non-microbial (seaweed extract or biochar) plant biostimulants should be promoted to reinforce sustainability efforts (González-González et al., 2020).

Global climate is changing rapidly than ever, menacing both plants and their symbiotic partners, thereby exerting significant direct and indirect effects on the growth and productivity of plants. Although AMF can attenuate the effects of abiotic stresses including climate change by fortifying the stress tolerance of host plants, their effects on AMF are given less attention, and hence poorly understood. Effects of these stresses on the symbiont could be direct or could be indirect through their impact on the host plant. It is expected that multiple abiotic stresses can directly affect the fitness, community composition, diversity, and symbiotic functioning of the fungi. Thus, keeping in mind the current scenario of global climate change and various other abiotic stresses, it is worth mentioning that studying the effects of abiotic stresses on AMF separately from plants will deliver a better understanding of the strengths and flaws of their ubiquitous relationship and for the employment of the AMF technology in sustainable agriculture.

In view of sustainable agriculture, the economical development of viable and potent AMF inocula to serve as bio fertilizer holds many practical applications; however, it is

\section{REFERENCES}

Abdel-Fattah, G. M., Ibrahim, A. H., Al-Amri, S. M., and Shoker, A. E. (2013). Synergistic effect of arbuscular mycorrhizal fungi and spermine on amelioration of salinity stress of wheat ('Triticum aestivum'L. cv. gimiza 9). Aust. J. Crop Sci. 7, 1525-1532.

Abeer, H., Abd Allah, E. F., Alqarawi, A. A., El-Didamony, G., Alwhibi, M., Egamberdieva, D., et al. (2014). Alleviation of adverse impact of salinity on faba bean (Vicia faba L.) by arbuscular mycorrhizal fungi. Pak. J. Bot. 46, 2003-2013.

Agre, P., Bonhivers, M., and Borgnia, M. J. (1998). The aquaporins, blueprints for cellular plumbing systems. J. Biol. Chem. 273, 14659-14662. doi: 10.1074/jbc.273.24.14659

Alam, M. Z., McGee, R., Hoque, M., Ahammed, G. J., and Carpenter-Boggs, L. (2019). Effect of arbuscular mycorrhizal fungi, selenium and biochar on photosynthetic pigments and antioxidant enzyme activity under arsenic stress still inadequate due to limited research capacity and technical complexities. Primary obstacles to large-scale production of AMF inocula are the following: (1) the obligate nature of the fungi, which makes the phase of crop cultivation a prerequisite and (2) the fear of contamination by weeds and pathogenic spores in soil-based inocula. Conducting an expansive openfield inoculation treatment seems economically prohibitive. However, if AM-friendly management (fall cover cropping and conservation tillage) is executed and AM-biodiversity is well-established, the fungal community will perpetuate and the hyphal networks will remain unaltered (Lehman et al., 2012; Berruti et al., 2016). A major step toward stable usage of AMF is to conduct wholesale field trials at diverse locations and analyze the cost-economy (Ceballos et al., 2013) in order to better aware the potential users of the advantages of AMF. Additionally, autonomous production of customized inocula from the native soil per se can be encouraged so as to make the strategy of bio fertilization and stress amelioration more economical for farmers of developing countries.

Taken together, AMF must be scouted on all levels to further examine their beneficial roles in the natural environment where plants are subjected to multiple stresses at a time; this would be imperative to make complete use of AMF as a bio fertilizer and stress mitigator in order to achieve sustainable agriculture production and guarantee food security.

\section{AUTHOR CONTRIBUTIONS}

KS and RK conceptualized the design, draft, and layout of the literature work. All the authors have critically reviewed the manuscript and approved it for submission.

\section{ACKNOWLEDGMENTS}

The authors jointly acknowledge the Science and Engineering Research Board (Grant no. SERB/CRG/2019/000836). RK acknowledges the Research Council of the University of Delhi for the publication support. KS, SG, and ST acknowledge the Council of Scientific and Industrial Research (CSIR) and PJ acknowledges the University Grants Commission (UGC) for fellowships.

in mung bean (Vigna radiata). Front. Physiol. 10:193. doi: 10.3389/fphys.2019. 00193

Alcázar, R., Altabella, T., Marco, F., Bortolotti, C., Reymond, M., Koncz, C., et al. (2010). Polyamines: molecules with regulatory functions in plant abiotic stress tolerance. Planta 231, 1237-1249. doi: 10.1007/s00425-010-1130-0

Alcazar, R., Garcia-Martinez, J. L., Cuevas, J. C., Tiburcio, A.,F., and Altabella, T. (2005). Overexpression of ADC2 in Arabidopsis induces dwarfism and late- flowering through GA deficiency. Plant J. 43, 421-436. doi: 10.1111/j.1365-313X.2005.02465.x

Almeida-Rodríguez, A. M., Gómes, M. P., Loubert-Hudon, A., Joly, S., and Labrecque, M. (2016). Symbiotic association between Salix purpurea L. and Rhizophagus irregularis: modulation of plant responses under copper stress. Tree Physiol. 36, 407-420. doi: 10.1093/treephys/tpv119

Anwar, R., Mattoo, A. K., and Handa, A. K. (2015). "Polyamine interactions with plant hormones: crosstalk at several levels," in Polyamines, eds T. Kusano, and H. Suzuki (Tokyo: Springer), 267-302. doi: 10.1007/978-4-431-55212-3_22 
Ariani, A., Barozzi, F., Sebastiani, L., di Toppi, L. S., di Sansebastiano, G. P., and Andreucci, A. (2019). AQUA1 is a mercury sensitive poplar aquaporin regulated at transcriptional and post-translational levels by $\mathrm{Zn}$ stress. Plant Physiol. Biochem. 135, 588-600. doi: 10.1016/j.plaphy.2018.10.038

Aroca, R., Porcel, R., and Ruiz-Lozano, J. M. (2007). How does arbuscular mycorrhizal symbiosis regulate root hydraulic properties and plasma membrane aquaporins in Phaseolus vulgaris under drought, cold or salinity stresses? New Phytol. 173, 808-816. doi: 10.1111/j.1469-8137.2006.01961.x

Aroca, R., and Ruiz-Lozano, J. M. (2009). "Induction of plant tolerance to semiarid environments by beneficial soil microorganisms-a review", in Climate Change, Intercropping, Pest Control and Beneficial Microorganisms. Sustainable Agriculture Reviews, ed E. Lichtfouse (Dordrecht: Springer), 121-135.

Bai, J., Lin, X., Yin, R., Zhang, H., Junhua, W., Xueming, C., et al. (2008). The influence of arbuscular mycorrhizal fungi on As and $\mathrm{P}$ uptake by maize (Zea mays L.) from As-contaminated soils. Appl. Soil Ecol. 38, 137-145. doi: 10.1016/j.apsoil.2007.10.002

Bárzana, G., Aroca, R., Bienert, G. P., Chaumont, F., and Ruiz-Lozano, J. M. (2014). New insights into the regulation of aquaporins by the arbuscular mycorrhizal symbiosis in maize plants under drought stress and possible implications for plant performance. Mol. Plant Microbe Interact. 27, 349-363. doi: 10.1094/MPMI-09-13-0268-R

Bárzana, G., Aroca, R., Paz, J. A., Chaumont, F., Martinez-Ballesta, M. C., Carvajal, M., et al. (2012). Arbuscular mycorrhizal symbiosis increases relative apoplastic water flow in roots of the host plant under both well-watered and drought stress conditions. Ann. Bot. 109, 1009-1017. doi: 10.1093/aob/mcs007

Beaudette, P. C., Chlup, M., Yee, J., and Emery, R. N. (2007). Relationships of root conductivity and aquaporin gene expression in Pisum sativum: diurnal patterns and the response to $\mathrm{HgCl}_{2}$ and ABA. J. Exp. Bot. 58, 1291-1300. doi: $10.1093 / \mathrm{jxb} / \mathrm{erl} 289$

Berruti, A., Lumini, E., Balestrini, R., and Bianciotto, V. (2016). Arbuscular mycorrhizal fungi as natural biofertilizers: let's benefit from past successes. Front. Microbiol. 6:1559. doi: 10.3389/fmicb.2015.01559

Berta, G., Sgorbati, S., Soler, V., Fusconi, A., Trotta, A., Citterio, A., et al. (1990). Variations in chromatin structure in host nuclei of a vesicular arbuscular mycorrhiza. New Phytol. 114, 199-205. doi: 10.1111/j.1469-8137.1990.tb00391.x

Besford, R. T., Richardson, C. M., Campos, J. L., and Tiburcio, A. F. (1993). Effect of polyamines on stabilization of molecular complexes in thylakoid membranes of osmotically stressed oat leaves. Planta 189, 201-206. doi: 10.1007/BF00195077

Bharti, A., Garg, S., Prakash, A., and Sharma, M. P. (2017). Contribution of AMF in the Remediation of Drought Stress in Soybean Plants. New Delhi: New India Publishing Agency.

Ceballos, I., Ruiz, M., Fernández, C., Peña, R., Rodríguez, A., and Sanders, I. R. (2013). The in vitro mass-produced model mycorrhizal fungus, Rhizophagus irregularis, significantly increases yields of the globally important food security crop cassava. PLoS ONE 8:e70633. doi: 10.1371/journal.pone. 0070633

Chakraborty, K., Sairam, R. K., and Bhaduri, D. (2016). Effects of different levels of soil salinity on yield attributes, accumulation of nitrogen, and micronutrients in Brassica spp. J. Plant. Nutr. 39, 1026-1037. doi: 10.1080/01904167.2015.1109105

Chen, D., Shao, Q., Yin, L., Younis, A., and Zheng, B. (2019). Polyamine function in plants: metabolism, regulation on development, and roles in abiotic stress responses. Front. Plant Sci. 9:1945. doi: 10.3389/fpls.2018. 01945

Chen, J., Zhang, H., Zhang, X., and Tang, M. (2017). Arbuscular mycorrhizal symbiosis alleviates salt stress in black locust through improved photosynthesis, water status, and $\mathrm{K}^{+} / \mathrm{Na}^{+}$homeostasis. Front. Plant Sci. 8:1739. doi: $10.3389 /$ fpls.2017.01739

Chen, X., Bründl, M., Friesacher, T., and Stary-Weinzinger, A. (2020). Computational insights into voltage dependence of polyamine block in a strong inwardly rectifying $\mathrm{K}^{+}$channel. Front. Pharmacol. 11:721. doi: 10.3389/fphar.2020.00721

Chen, X., Li, H., Chan, W. F., Wu, C., Wu, F., Wu, S., et al. (2012). Arsenite transporters expression in rice (Oryza sativa L.) associated with arbuscular mycorrhizal fungi (AMF) colonization under different levels of arsenite stress. Chemosphere 89, 1248-1254. doi: 10.1016/j.chemosphere.2012. 07.054
Christie, P., Li, X., and Chen, B. (2004). Arbuscular mycorrhiza can depress translocation of zinc to shoots of host plants in soils moderately polluted with zinc. Plant Soil 261, 209-217. doi: 10.1023/B:PLSO.0000035542.79345.1b

Cicatelli, A., Lingua, G., Todeschini, V., Biondi, S., Torrigiani, P., and Castiglione, S. (2010). Arbuscular mycorrhizal fungi restore normal growth in a white poplar clone grown on heavy metal-contaminated soil, and this is associated with upregulation of foliar metallothionein and polyamine biosynthetic gene expression. Ann. Bot. 106, 791-802. doi: 10.1093/aob/mcq170

Cicatelli, A., Torrigiani, P., Todeschini, V., Biondi, S., Castiglione, S., and Lingua, G. (2014). Arbuscular mycorrhizal fungi as a tool to ameliorate the phytoremediation potential of poplar: biochemical and molecular aspects. iForest 7, 333-349. doi: 10.3832/ifor1045-007

Cuevas, J. C., Lopez-Cobollo, R., Alcazar, R., Zarza, X., Koncz, C., Altabella, T., et al. (2008). Putrescine is involved in Arabidopsis freezing tolerance and cold acclimation by regulating abscisic acid levels in response to low temperature. Plant Physiol. 148, 1094-1105. doi: 10.1104/pp.108.122945

Ding, Y. E., Fan, Q. F., He, J. D., Wu, H. H., Zou, Y. N., Wu, Q. S., et al. (2020). Effects of mycorrhizas on physiological performance and root TIPS expression in trifoliate orange under salt stress. Arch. Agron. Soil Sci. 66, 182-192. doi: 10.1080/03650340.2019.1607313

Dubois, M., Van den Broeck, L., and Inzé, D. (2018). The pivotal role of ethylene in plant growth. Trends Plant Sci. 23, 311-323. doi: 10.1016/j.tplants.2018.01.003

Echeverria, M., Sannazzaro, A. I., Ruiz, O. A., and Menéndez, A. B. (2013). Modulatory effects of Mesorhizobium tianshanense and Glomus intraradices on plant proline and polyamine levels during early plant response of Lotus tenuis to salinity. Plant Soil 364, 69-79. doi: 10.1007/s11104-012-1312-6

Egamberdieva, D., Jabborova, D., and Wirth, S. (2013). "Alleviation of salt stress in legumes by co-inoculation with Pseudomonas and Rhizobium", in Plant Microbe Symbiosis: Fundamentals and Advances, ed N. Aroca (New Delhi: Springer), 291-303.

El Ghachtouli, N., Paynot, M., Morandi, D., Martin-Tanguy, J., and Gianinazzi, S. (1995). The effect of polyamines on endomycorrhizal infection of wild-type Pisum sativum, cv. Frisson (nod+ myc+) and two mutants (nod- myc+ and nod- myc-). Mycorrhiza 5, 189-192. doi: 10.1007/s005720050058

Espasandin, F. D., Maiale, S. J., Calzadilla, P., Ruiz, O. A., and Sansberro, P. A. (2014). Transcriptional regulation of 9-cis-epoxycarotenoid dioxygenase (NCED) gene by putrescine accumulation positively modulates ABA synthesis and drought tolerance in Lotustenuis plants. Plant Physiol. Biochem. 76, 29-35. doi: 10.1016/j.plaphy.2013.12.018

Evelin, H., Devi, T. S., Gupta, S., and Kapoor, R. (2019). Mitigation of salinity stress in plants by arbuscular mycorrhizal symbiosis: current understanding and new challenges. Front. Plant Sci. 10:470. doi: 10.3389/fpls.2019.00470

Evelin, H., Giri, B., and Kapoor, R. (2012). Contribution of Glomus intraradices inoculation to nutrient acquisition and mitigation of ionic imbalance in NaCl-stressed Trigonella foenum-graecum. Mycorrhiza 22, 203-217. doi: $10.1007 / \mathrm{s} 00572-011-0392-0$

Evelin, H., Giri, B., and Kapoor, R. (2013). Ultrastructural evidence for AMF mediated salt stress mitigation in Trigonella foenum-graecum. Mycorrhiza 23, 71-86. doi: 10.1007/s00572-012-0449-8

Evelin, H., Kapoor, R., and Giri, B. (2009). Arbuscular mycorrhizal fungi in alleviation of salt stress: a review. Ann. Bot. 104, 1263-1280. doi: $10.1093 / \mathrm{aob} / \mathrm{mcp} 251$

Even-Chen, Z., Mattoo, A. K., and Goren, R. (1982). Inhibition of ethylene biosynthesis by aminoethoxyvinylglycine and by polyamines shunts label from $3,4-[14 \mathrm{C}]$ methionine into spermidine in aged orange peel discs. Plant Physiol. 69, 385-388. doi: 10.1104/pp.69.2.385

Ezawa, T., Smith, S. E., and Smith, F. A. (2002). P metabolism and transport in AM fungi. Plant Soil 244, 221-230. doi: 10.1023/A:1020258325010

FAO (2017) The Future of Food and Agriculture - Trends and Challenges. Roeme.

Fatemi, H., Zaghdoud, C., Nortes, P. A., Carvajal, M., and Martínez-Ballesta, M. D. C. (2020). Differential aquaporin response to distinct effects of two Zn concentrations after foliar application in pak choi (Brassica rapa L.) plants. Agronomy 10:450. doi: 10.3390/agronomy10030450

Flowers, T. J., Garcia, A., Koyama, M., and Yeo, A. R. (1997). Breeding for salt tolerance in crop plants-the role of molecular biology. Acta Physiol. Plant 19, 427-433. doi: 10.1007/s11738-997-0039-0

Flowers, T. J., and Yeo, A. R. (1995). Breeding for salinity resistance in crop plants: where next? Funct. Plant Biol. 22, 875-884. doi: 10.1071/PP9950875 
Foo, E., McAdam, E. L., Weller, J. L., and Reid, J. B. (2016). Interactions between ethylene, gibberellins, and brassinosteroids in the development of rhizobial and mycorrhizal symbioses of pea. J. Exp. Bot. 67, 2413-2424. doi: $10.1093 / \mathrm{jxb} / \mathrm{erw} 047$

Freschi, L. (2013). Nitric oxide and phytohormone interactions: current status and perspectives. Front. Plant Sci. 4:398. doi: 10.3389/fpls.2013.00398

Galston, A. W., and Sawhney, R. K. (1990). Polyamines in plant physiology. Plant Physiol. 94, 406-410. doi: 10.1104/pp.94.2.406

Garg, N., and Bhandari, P. (2016). Interactive effects of silicon and arbuscular mycorrhiza in modulating ascorbate-glutathione cycle and antioxidant scavenging capacity in differentially salt-tolerant Cicerarietinum L. genotypes subjected to long-term salinity. Protoplasma 253, 1325-1345. doi: 10.1007/s00709-015-0892-4

Garg, N., and Saroy, K. (2020). Interactive effects of polyamines and arbuscular mycorrhiza in modulating plant biomass, $\mathrm{N}_{2}$ fixation, ureide, and trehalose metabolism in Cajanus cajan (L.) Millsp.genotypes under nickel stress. Environ. Sci. Pollut. Res. 27, 3043-3064. doi: 10.1007/s11356-019-07300-6

Goicoechea, N., Szalai, G., Antolín, M. C., Sánchez-Díaz, M., and Paldi, E. (1998). Influence of arbuscular mycorrhizae and Rhizobium on free polyamines and proline levels in water-stressed alfalfa. J. Plant Physiol. 153, 706-711. doi: 10.1016/S0176-1617(98)80224-1

Gonzalez, M. E., Marco, F., Minguet, E. G., Carrasco-Sorli, P., Blázquez, M. A., Carbonell, J., et al. (2011). Perturbation of spermine synthase gene expression and transcript profiling provide new insights on the role of the tetraamine spermine in Arabidopsis defense against Pseudomonasviridiflava. Plant Physiol. 156, 2266-2277. doi: 10.1104/pp.110.171413

González-González, M. F., Ocampo-Alvarez, H., Santacruz-Ruvalcaba, F., Sánchez-Hernández, C. V., Casarrubias-Castillo, K., Becerril-Espinosa, A., et al. (2020). Physiological, ecological, and biochemical implications in tomato plants of two plant biostimulants: arbuscular mycorrhizal fungi and seaweed extract. Front. Plant Sci. 11:999. doi: 10.3389/fpls.2020.00999

Groppa, M. D., Tomaro, M. L., and Benavides, M. P. (2007). Polyamines and heavy metal stress: the antioxidant behavior of spermine in cadmium- and coppertreated wheat leaves. Biometals 20, 185-195. doi: 10.1007/s10534-006-9026-y

Gupta, S., Thokchom, S. D., and Kapoor, R. (2021). Arbuscular mycorrhiza improves photosynthesis and restores alteration in sugar metabolism in Triticum aestivum L. grown in arsenic contaminated soil. Front. Plant Sci. 12:334. doi: 10.3389/fpls.2021.640379

Gusman, G. S., Oliveira, J. A., Farnese, F. S., and Cambraia, J. (2013). Mineral nutrition and enzymatic adaptation induced by arsenate and arsenite exposure in lettuce plants. Plant Physiol. Biochem. 71, 307-314. doi: 10.1016/j.plaphy.2013.08.006

Hanfrey, C., Sommer, S., Mayer, M. J., Burtin, D., and Michael, A. J. (2001). Arabidopsis polyamine biosynthesis: absence of ornithine decarboxylase and the mechanism of arginine decarboxylase activity. Plant J. 27, 551-560. doi: 10.1046/j.1365-313X.2001.01100.x

Hashem, A., Abd-Allah, E. F., Alqarawi, A. A., Al-Huqail, A. A., Wirth, S., and Egamberdieva, D. (2016). The interaction between arbuscular mycorrhizal fungi and endophytic bacteria enhances plant growth of Acacia gerrardii under salt stress. Front. Microbiol. 7:1089. doi: 10.3389/fmicb.2016.01089

Hashem, A., Alqarawi, A. A., Radhakrishnan, R., Al-Arjani, A. B. F., Aldehaish, H. A., Egamberdieva, D., et al. (2018). Arbuscular mycorrhizal fungi regulate the oxidative system, hormones and ionic equilibrium to trigger salt stress tolerance in Cucumissativus L. Saudi J. Biol. Sci. 25, 1102-1114. doi: $10.1016 /$ j.sjbs.2018.03.009

He, F., Zhang, H., and Tang, M. (2016). Aquaporin gene expression and physiological responses of Robinia pseudoacacia L. to the mycorrhizal fungus Rhizophagus irregularis and drought stress. Mycorrhiza 26, 311-323. doi: $10.1007 / \mathrm{s} 00572-015-0670-3$

Hidri, R., Mahmoud, O. M. B., Debez, A., Abdelly, C., Barea, J. M., and Azcon, R. (2019). Modulation of C: N: P stoichiometry is involved in the effectiveness of a PGPR and AM fungus in increasing salt stress tolerance of Sulla carnosa Tunisian provenances. Appl. Soil Ecol. 143, 161-172. doi: 10.1016/j.apsoil.2019.06.014

Hu, Y., and Chen, B. (2020). Arbuscular mycorrhiza induced putrescine degradation into $\gamma$-aminobutyric acid, malic acid accumulation, and improvement of nitrogen assimilation in roots of water-stressed maize plants. Mycorrhiza 30, 329-339. doi: 10.1007/s00572-020-00952-0
Hu, Y., Xie, W., and Chen, B. (2020). Arbuscular mycorrhiza improved drought tolerance of maize seedlings by altering photosystem II efficiency and the levels of key metabolites. Chem. Biol. Technol. Agric. 7, 1-14. doi: 10.1186/s40538-020-00186-4

Hura, T., Dziurka, M., Hura, K., Ostrowska, A., and Dziurka, K. (2015). Free and cell wall-bound polyamines under long-term water stress applied at different growth stages of $\times$ Triticosecale Wittm. PloS ONE 10:e0135002. doi: 10.1371/journal.pone. 0135002

Ibrahim, A. H., Abdel-Fattah, G. M., Eman, F. M., Abd El-Aziz, M. H., and Shohr, A. E. (2011). Arbuscular mycorrhizal fungi and spermine alleviate the adverse effects of salinity stress on electrolyte leakage and productivity of wheat plants. Phyton Int. J. Exp. Bot. 51, 261-276.

Igiehon, N. O., Babalola, O. O., Cheseto, X., and Torto, B. (2020). Effects of rhizobia and arbuscular mycorrhizal fungi on yield, size distribution and fatty acid of soybean seeds grown under drought stress. Microbiol. Res. 242:126640. doi: 10.1016/j.micres.2020.126640

Iqbal, N., Umar, S., Khan, N. A., and Khan, M. I. R. (2014). A new perspective of phytohormones in salinity tolerance: regulation of proline metabolism. Environ. Exp. Bot. 100, 34-42. doi: 10.1016/j.envexpbot.2013.12.006

Ishikawa, F., Suga, S., Uemura, T., Sato, M. H., and Maeshima, M. (2005). Novel type aquaporin SIPs are mainly localized to the ER membrane and show cell-specific expression in Arabidopsis thaliana. FEBS Lett. 579, 5814-5820. doi: 10.1016/j.febslet.2005.09.076

Jahromi, F., Aroca, R., Porcel, R., and Ruiz-Lozano, J. M. (2008). Influence of salinity on the in vitro development of Glomus intraradices and on the in vivo physiological and molecular responses of mycorrhizal lettuce plants. Microb. Ecol. 55:45. doi: 10.1007/s00248-007-9249-7

Jaleel, C. A., Manivannan, P., Wahid, A., Farooq, M., Al-Juburi, H. J., Somasundaram, R., et al. (2009). Drought stress in plants: a review on morphological characteristics and pigments composition. Int. J. Agric. Biol. $11,100-105$.

Javot, H., and Maurel, C. (2002). The role of aquaporins in root water uptake. Ann. Bot. 90, 301-313. doi: 10.1093/aob/mcf199

Jia-Dong, H., Tao, D., Hui-Hui, W., Ying-Ning, Z., Qiang-Sheng, W., and Kamil, K. (2019). Mycorrhizas induce diverse responses of root TIP aquaporin gene expression to drought stress in trifoliate orange. Sci. Hortic. 243, 64-69. doi: $10.1016 /$ j.scienta.2018.08.010

Juniper, S., and Abbott, L. (1993). Vesicular-arbuscular mycorrhizas and soil salinity. Mycorrhiza 4, 45-57. doi: 10.1007/BF00204058

Kakkar, R. K., and Sawhney, V. K. (2002). Polyamine research in plants-a changing perspective. Physiol. Plant 116, 281-292. doi: $10.1034 /$ j.1399-3054.2002.1160302.x

Kapilan, R., Vaziri, M., and Zwiazek, J. J. (2018). Regulation of aquaporins in plants under stress. Biol. Res. 51, 1-11. doi: 10.1186/s40659-018-0152-0

Khalid, M., Saeed, U. R., Hassani, D., Hayat, K., Pei, Z. H. O. U., and Nan, H. U. I. (2021). Advances in fungal-assisted phytoremediation of heavy metals: a review. Pedosphere 31, 475-495. doi: 10.1016/S1002-0160(20) 60091-1

Khalloufi, M., Martínez-Andújar, C., Lachaâl, M., Karray-Bouraoui, N., PérezAlfocea, F., and Albacete, A. (2017). The interaction between foliar GA3 application and arbuscular mycorrhizal fungi inoculation improves growth in salinized tomato (Solanumlycopersicum L.) plants by modifying the hormonal balance. J. Plant Physiol. 214, 134-144. doi: 10.1016/j.jplph.2017.04.012

Kholodova, V., Volkov, K., Abdeyeva, A., and Kuznetsov, V. (2011). Water status in Mesembryanthemum crystallinum under heavy metal stress. Environ. Exp. Bot. 71, 382-389. doi: 10.1016/j.envexpbot.2011.02.007

Khoshbakht, D., Asghari, M. R., and Haghighi, M. (2018). Influence of foliar application of polyamines on growth, gas-exchange characteristics, and chlorophyll fluorescence in Bakraii citrus under saline conditions. Photosynthetica 56, 731-742. doi: 10.1007/s11099-017-0723-2

Kourghi, M., Nourmohammadi, S., Pei, J. V., Qiu, J., McGaughey, S., Tyerman, S. D., et al. (2017). Divalent cations regulate the ion conductance properties of diverse classes of aquaporins. Int. J. Mol. Sci. 18:2323. doi: 10.3390/ijms18112323

Krajinski, F., Biela, A., Schubert, D., Gianinazzi-Pearson, V., Kaldenhoff, R., and Franken, P. (2000). Arbuscular mycorrhiza development regulates the mRNA abundance of Mtaqp1 encoding a mercury-insensitive aquaporin of Medicago truncatula. Planta 211, 85-90. doi: 10.1007/s004250000263 
Lazzarato, L., Trebbi, G., Pagnucco, C., Franchin, C., Torrigiani, P., and Betti, L. (2009). Exogenous spermidine, arsenic and $\beta$-aminobutyric acid modulate tobacco resistance to tobacco mosaic virus, and affect local and systemic glucosyl salicylic acid levels and arginine decarboxylase gene expression in tobacco leaves. J. Plant Physiol. 166, 90-100. doi: 10.1016/j.jplph.2008.01.011

Lehman, R. M., Taheri, W. I., Osborne, S. L., Buyer, J. S., and Douds, D. D. Jr. (2012). Fall cover cropping can increase arbuscular mycorrhizae in soils supporting intensive agricultural production. Appl. Soil Ecol. 61, 300-304. doi: 10.1016/j.apsoil.2011.11.008

Li, M., Lu, J., Tao, M., Li, M., Yang, H., Xia, E. H., et al. (2020). Genomewide identification of seven polyamine oxidase genes in Camellia sinensis (L.) and their expression patterns under various abiotic stresses. Front. Plant Sci. 11:1338. doi: 10.3389/fpls.2020.544933

Li, S., Jin, H., and Zhang, Q. (2016). The effect of exogenous spermidine concentration on polyamine metabolism and salt tolerance in Zoysiagrass (Zoysia japonica Steud.) subjected to short-term salinity stress. Front. Plant Sci. 7:1221. doi: 10.3389/fpls.2016.01221

Li, T., Hu, Y. J., Hao, Z. P., Li, H., and Chen, B. D. (2013). Aquaporin genes GintAQPF1 and GintAQPF2 from Glomus intraradices contribute to plant drought tolerance. Plant Signal. Behav. 8:e24030. doi: 10.4161/psb.24030

Li, Z., Zhang, Y., Peng, D., Peng, Y., Zhang, X., Ma, X., et al. (2018). The inhibition of polyamine biosynthesis weakens the drought tolerance in white clover (Trifolium repens) associated with the alteration of extensive proteins. Protoplasma 255, 803-817. doi: 10.1007/s00709-017-1186-9

Li, Z., Zhang, Y., Zhang, X., Peng, Y., Merewitz, E., Ma, X., et al. (2016). The alterations of endogenous polyamines and phytohormones induced by exogenous application of spermidine regulate antioxidant metabolism, metallothionein and relevant genes conferring drought tolerance in white clover. Environ. Exp. Bot. 124, 22-38. doi: 10.1016/j.envexpbot.2015.12.004

Lin, C. C., and Kao, C. H. (1999). Excess copper induces an accumulation of putrescine in rice leaves. Bot. Bull. Acad. Sin. 40, 213-218.

Liu, C., Zhao, X., Yan, J., Yuan, Z., and Gu, M. (2020). Effects of salt stress on growth, photosynthesis, and mineral nutrients of 18 pomegranate (Punica granatum) cultivars. Agronomy 10:27. doi: 10.3390/agronomy10010027

Liu, K., Fu, H., Bei, Q., and Luan, S. (2000). Inward potassium channel in guard cells as a target for polyamine regulation of stomatal movements. Plant Physiol. 124, 1315-1326. doi: 10.1104/pp.124.3.1315

Liu, M., Chen, J., Guo, Z., and Lu, S. (2017). Differential responses of polyamines and antioxidants to drought in a centipede grass mutant in comparison to its wild type plants. Front. Plant Sci. 8:792. doi: 10.3389/fpls.2017.00792

Liu, T., Kim, D. W., Niitsu, M., Berberich, T., and Kusano, T. (2014). Oryza sativa polyamine oxidase 1 back-converts tetraamines, spermine and thermospermine, to spermidine. Plant Cell Rep. 33, 143-151. doi: 10.1007/s00299-013-1518-y

Liu, Y., Liang, H., Lv, X., Liu, D., Wen, X., and Liao, Y. (2016). Effect of polyamines on the grain filling of wheat under drought stress. Plant Physiol. Biochem. 100, 113-129. doi: 10.1016/j.plaphy.2016.01.003

Luo, Y. (2009). Effects of AMF on Cell Membrane, Endogenous Polyamines, and Salicylic Acid in Citrus Under Drought Stress. Huazhong Agriculture University.

Ma, J. F., Yamaji, N., Mitani, N., Xu, X. Y., Su, Y. H., McGrath, S. P., et al. (2008). Transporters of arsenite in rice and their role in arsenic accumulation in rice grain. Proc. Natl. Acad. Sci. U.S.A. 105, 9931-9935. doi: 10.1073/pnas.0802361105

Marjanović, Ž., Uehlein, N., Kaldenhoff, R., Zwiazek, J. J., Weiß, M., Hampp, R., et al. (2005). aquaporins in poplar: what a difference a symbiont makes!. Planta 222, 258-268. doi: 10.1007/s00425-005-1539-z

Marulanda, A., Azcon, R., and Ruiz-Lozano, J. M. (2003). Contribution of six arbuscular mycorrhizal fungal isolates to water uptake by Lactuca sativa plants under drought stress. Physiol. Plant 119, 526-533. doi: 10.1046/j.1399-3054.2003.00196.x

Mattoo, A. K., and White, W. B. (2018). Regulation of Ethylene Biosynthesis in Plant Hormone Ethylene. Boca Raton, FL: CRC Press, 21-42.

Maurel, C. (2007). Plant aquaporins: novel functions and regulation properties. FEBS Let. 581, 2227-2236. doi: 10.1016/j.febslet.2007.03.021

Mekonnen, D. W., Flügge, U. I., and Ludewig, F. (2016). Gamma-aminobutyric acid depletion affects stomata closure and drought tolerance of Arabidopsis thaliana. Plant Sci. 245, 25-34. doi: 10.1016/j.plantsci.2016.01.005
Menéndez, A. B., Calzadilla, P. I., Sansberro, P. A., Espasandin, F. D., Gazquez, A., Bordenave, C. D., et al. (2019). Polyamines and legumes: Joint stories of stress, nitrogen fixation and environment. Front. Plant Sci. 10:1415. doi: 10.3389/fpls.2019.01415

Merlos, M. A., Zitka, O., Vojtech, A., Azcón-Aguilar, C., and Ferrol, N. (2016). The arbuscular mycorrhizal fungus Rhizophagus irregularis differentially regulates the copper response of two maize cultivars differing in copper tolerance. Plant Sci. 253, 68-76. doi: 10.1016/j.plantsci.2016.09.010

Mo, H., Wang, X., Zhang, Y., Zhang, G., Zhang, J., and Ma, Z. (2015). Cotton polyamine oxidase is required for spermine and camalexin signaling in the defence response to Verticillium dahliae. Plant J. 83, 962-975. doi: $10.1111 /$ tpj.12941

Mohapatra, S., Minocha, R., Long, S., and Minocha, S. C. (2009). Putrescine overproduction negatively impacts the oxidative state of poplar cells in culture. Plant Physiol. Biochem. 47, 262-271. doi: 10.1016/j.plaphy.2008.12.007

Nahar, K., Hasanuzzaman, M., Alam, M. M., Rahman, A., Suzuki, T., and Fujita, M. (2016). Polyamine and nitric oxide crosstalk: antagonistic effects on cadmium toxicity in mung bean plants through upregulating the metal detoxification, antioxidant defense and methylglyoxal detoxification systems. Ecotoxicol. Environ. Saf. 126, 245-255. doi: 10.1016/j.ecoenv.2015.12.026

Niemi, K., Sutela, S., Häggman, H., Scagel, C., Vuosku, J., Jokela, A., et al. (2006). Changes in polyamine content and localization of Pinus sylvestris ADC and Suillus variegatus ODC mRNA transcripts during the formation of mycorrhizal interaction in an in vitro cultivation system. J. Exp. Bot. 57, 2795-2804. doi: $10.1093 / \mathrm{jxb} / \mathrm{erl} 049$

Nogales, A., Aguirreolea, J., Santa María, E., Camprubí, A., and Calvet, C. (2009). Response of mycorrhizal grapevine to Armillaria mellea inoculation: disease development and polyamines. Plant Soil 317:177. doi: 10.1007/s11104-008-9799-6

Noronha, H., Araújo, D., Conde, C., Martins, A. P., Soveral, G., Chaumont, F., et al. (2016). The grapevine uncharacterized intrinsic protein 1 ( VvXIP1) is regulated by drought stress and transports glycerol, hydrogen peroxide, heavy metals but not water. PloS ONE 11:e0160976. doi: 10.1371/journal.pone.0160976

Ouziad, F., Wilde, P., Schmelzer, E., Hildebrandt, U., and Bothe, H. (2006). Analysis of expression of aquaporins and $\mathrm{Na}^{+} / \mathrm{H}^{+}$transporters in tomato colonized by arbuscular mycorrhizal fungi and affected by salt stress. Environ. Exp. Bot. 57, 177-186. doi: 10.1016/j.envexpbot.2005.05.011

Ozawa, R., Bertea, C. M., Foti, M., Narayana, R., Arimura, G. I., Muroi, A., et al. (2009). Exogenous polyamines elicit herbivore-induced volatiles in lima bean leaves: involvement of calcium, $\mathrm{H}_{2} \mathrm{O}_{2}$ and Jasmonic acid. Plant Cell Physiol. 50, 2183-2199. doi: 10.1093/pcp/pcp153

Pál, M., Csávás, G., Szalai, G., Oláh, T., Khalil, R., Yordanova, R., et al. (2017). Polyamines may influence phytochelatin synthesis during $\mathrm{Cd}$ stress in rice. J. Hazard. Mater. 340, 272-280. doi: 10.1016/j.jhazmat.2017.07.016

Pál, M., Szalai, G., and Janda, T. (2015). Speculation: polyamines are important in abiotic stress signaling. Plant Sci. 237, 16-23. doi: $10.1016 /$ j.plantsci.2015.05.003

Parádi, I. (2003). Influence of arbuscular mycorrhiza and cadmium on the polyamine contents of Ri T-DNA transformed Daucus carota L. root cultures. Acta Biol. Szeged 47, 31-36.

Parvin, S., Lee, O. R., Sathiyaraj, G., Khorolragchaa, A., Kim, Y. J., and Yang, D. C. (2014). Spermidine alleviates the growth of saline-stressed ginseng seedlings through antioxidative defense system. Gene 537, 70-78. doi: 10.1016/j.gene.2013.12.021

Podlešáková, K., Ugena, L., Spíchal, L., DoleŽal, K., and De Diego, N. (2018). Phytohormones and polyamines regulate plant stress responses by altering GABA pathway. New Biotechnol. 48, 53-65. doi: 10.1016/j.nbt.2018.07.003

Popovic, R. B., Kyle, D. J., Cohen, A. S., and Zalik, S. (1979). Stabilization of thylakoid membranes by spermine during stress-induced senescence of barley leaf discs. Plant Physiol. 64, 721-726. doi: 10.1104/pp.64.5.721

Porcel, R., Aroca, R., Azcon, R., and Ruiz-Lozano, J. M. (2006). PIP aquaporin gene expression in arbuscular mycorrhizal Glycine max and Lactuca sativa plants in relation to drought stress tolerance. Plant Mol. Biol. 60, 389-404. doi: 10.1007/s11103-005-4210-y

Porcel, R., Aroca, R., and Ruiz-Lozano, J. M. (2012). Salinity stress alleviation using arbuscular mycorrhizal fungi: a review. Agro Sustain. Dev. 32, 181-200. doi: 10.1007/s13593-011-0029-x 
Porcel, R., Gómez, M., Kaldenhoff, R., and Ruiz-Lozano, J. M. (2005). Impairment of NtAQP1 gene expression in tobacco plants does not affect root colonisation pattern by arbuscular mycorrhizal fungi but decreases their symbiotic efficiency under drought. Mycorrhiza 15, 417-423. doi: 10.1007/s00572-005-0346-5

Priya, M., Sharma, L., Kaur, R., Bindumadhava, H., Nair, R. M., Siddique, K. H. M., et al. (2019). GABA ( $\gamma$-aminobutyric acid), as a thermo-protectant, to improve the reproductive function of heat-stressed mungbean plants. Sci. Rep. 9, 1-14. doi: 10.1038/s41598-019-44163-w

Przedpelska-Wasowicz, E. M., and Wierzbicka, M. (2011). Gating of aquaporins by heavy metals in Allium cepa L. epidermal cells. Protoplasma 248, 663-671. doi: 10.1007/s00709-010-0222-9

Quiroga, G., Erice, G., Aroca, R., Chaumont, F., and Ruiz-Lozano, J. M. (2019a). Contribution of the arbuscular mycorrhizal symbiosis to the regulation of radial root water transport in maize plants under water deficit. Environ. Exp. Bot. 167, 103-821. doi: 10.1016/j.envexpbot.2019.103821

Quiroga, G., Erice, G., Aroca, R., Zamarreño, Á. M., García-Mina, J. M., and RuizLozano, J. M. (2020). Radial water transport in arbuscular mycorrhizal maize plants under drought stress conditions is affected by indole-acetic acid (IAA) application. J. Plant Physiol. 246:153115. doi: 10.1016/j.jplph.2020.153115

Quiroga, G., Erice, G., Ding, L., Chaumont, F., Aroca, R., and Ruiz-Lozano, J. M. (2019b). The arbuscular mycorrhizal symbiosis regulates aquaporins activity and improves root cell water permeability in maize plants subjected to water stress. Plant Cell Environ. 42, 2274-2290. doi: 10.1111/pce.13551

Radhakrishnan, R., and Lee, I. J. (2013a). Regulation of salicylic acid, jasmonic acid and fatty acids in cucumber (Cucumissativus L.) by spermidine promotes plant growth against salt stress. Acta Physiol. Plant 35, 3315-3322. doi: 10.1007/s11738-013-1364-0

Radhakrishnan, R., and Lee, I. J. (2013b). Spermine promotes acclimation to osmotic stress by modifying antioxidant, abscisic acid, and jasmonic acid signals in soybean. J. Plant Growth Regul. 32, 22-30. doi: 10.1007/s00344-012-9274-8

Rady, M. M., and Hemida, K. A. (2015). Modulation of cadmium toxicity and enhancing cadmium-tolerance in wheat seedlings by exogenous application of polyamines. Ecotoxicol. Environ. Saf. 119,178-185. doi: 10.1016/j.ecoenv.2015.05.008

Rangan, P., Subramani, R., Kumar, R., Singh, A. K., and Singh, R. (2014). Recent advances in polyamine metabolism and abiotic stress tolerance. BioMed Res. Int. 2014:239621. doi: 10.1155/2014/239621

Ren, C. G., Kong, C. C., and Xie, Z. H. (2018). Role of abscisic acid in strigolactoneinduced salt stress tolerance in arbuscular mycorrhizal Sesbania cannabina seedlings. BMC Plant Biol. 18:74. doi: 10.1186/s12870-018-1292-7

Rezvanypour, S., Hatamzadeh, A., Elahinia, S. A., and Asghari, H. R. (2015). Exogenous polyamines improve mycorrhizal development and growth and flowering of Freesia hybrida. J. Hortic. Res. 23, 17-25. doi: $10.2478 /$ johr-2015-0013

Roser, M., Ritchie, H., and Ortiz-Ospina, E. (2013). World Population Growth. Our World in Data. Available online at: https://ourworldindata.org/worldpopulation-growth

Roussel, H., Bruns, S., Gianinazzi-Pearson, V., Hahlbrock, K., and Franken, P. (1997). Induction of a membrane intrinsic protein-encoding mRNA in arbuscular mycorrhiza and elicitor-stimulated cell suspension cultures of parsley. Plant Sci. 126, 203-210. doi: 10.1016/S0168-9452(97)00106-4

Rucińska-Sobkowiak, R. (2016). Water relations in plants subjected to heavy metal stresses. Acta Physiol. Plant 38:257. doi: 10.1007/s11738-016-2277-5

Ruiz-Lozano, J. M., and Aroca, R. (2010). "Host response to osmotic stresses: stomatal behaviour and water use efficiency of arbuscular mycorrhizal plants," in Arbuscular Mycorrhizas: Physiology and Function, eds H. Koltai, and Y. Kapulnik (Dordrecht: Springer), 239-256. doi: 10.1007/978-90-481-9489-6_11

Ruiz-Lozano, J. M., and Aroca, R. (2017). "Plant aquaporins and mycorrhizae: their regulation and involvement in plant physiology and performance," in Plant Aquaporins. Signaling and Communication in Plants, eds F. Chaumont, and S. Tyerman (Cham: Springer), 333-353. doi: 10.1007/978-3-319-49395-4_15

Ruiz-Lozano, J. M., del Mar Alguacil, M., Bárzana, G., Vernieri, P., and Aroca, R. (2009). Exogenous ABA accentuates the differences in root hydraulic properties between mycorrhizal and non mycorrhizal maize plants through regulation of PIP aquaporins. Plant Mol. Biol. 70:65. doi: 10.1007/s11103-009-9492-Z

Sade, D., Brotman, Y., Eybishtz, A., Cuadros-Inostroza, Á., Fernie, A. R., Willmitzer, L., et al. (2013). Involvement of the hexose transporter gene LeHT1 and of sugars in resistance of tomato to tomato yellow leaf curl virus. Mol. Plant 6, 1707-1710. doi: 10.1093/mp/sst036

Sannazzaro, A. I., Echeverría, M., Albertó, E. O., Ruiz, O. A., and Menéndez, A. B. (2007). Modulation of polyamine balance in Lotus glaber by salinity and arbuscular mycorrhiza. Plant Physiol. Biochem. 45, 39-46. doi: 10.1016/j.plaphy.2006.12.008

Santander, C., Aroca, R., Cartes, P., Vidal, G., and Cornejo, P. (2021). Aquaporins and cation transporters are differentially regulated by two arbuscular mycorrhizal fungi strains in lettuce cultivars growing under salinity conditions. Plant Physiol. Biochem. 158, 396-409. doi: 10.1016/j.plaphy.2020.11.025

Saroy, K., and Garg, N. (2021). Relative effectiveness of arbuscular mycorrhiza and polyamines in modulating ROS generation and ascorbate-glutathione cycle in Cajanus cajanunder nickel stress. ESPR 1-18. doi: 10.1007/s11356-021-13878-7

Schnurbusch, T., Hayes, J., Hrmova, M., Baumann, U., Ramesh, S. A., Tyerman, S. D., et al. (2010). Boron toxicity tolerance in barley through reduced expression of the multifunctional aquaporin HvNIP2; 1. Plant Physiol. 153, 1706-1715. doi: $10.1104 /$ pp.110.158832

Sequera-Mutiozabal, M., Antoniou, C., Tiburcio, A. F., Alcázar, R., and Fotopoulos, V. (2017). Polyamines: emerging hubs promoting drought and salt stress tolerance in plants. Curr. Mol. Biol. Rep. 3, 28-36. doi: 10.1007/s40610-017-0052-z

Serafini-Fracassini, D., Torrigiani, P., and Branca, C. (1984). Polyamines bound to nucleic acids during dormancy and activation of tuber cells of Helianthus tuberosus. Physiol. Plant 60, 351-357. doi: 10.1111/j.1399-3054.1984.tb06075.x

Shahid, M. A., Balal, R. M., Khan, N., Rossi, L., Rathinasabapathi, B., Liu, G., et al. (2018). Polyamines provide new insights into the biochemical basis of Cr-tolerance in Kinnow mandarin grafted on diploid and double-diploid rootstocks. Environ. Exp. Bot. 156, 248-260. doi: 10.1016/j.envexpbot.2018.09.015

Sharma, A., Shahzad, B., Kumar, V., Kohli, S. K., Sidhu, G. P. S., and Bali, A. S. (2019). Phytohormones regulate accumulation of osmolytes under abiotic stress. Biomolecules 9, 285-297. doi: 10.3390/biom9070285

Sharma, S., Anand, G., Singh, N., and Kapoor, R. (2017). Arbuscular mycorrhiza augments arsenic tolerance in wheat (Triticum aestivum L.) by strengthening antioxidant defense system and thiol metabolism. Front. Plant Sci. 8:906. doi: $10.3389 /$ fpls.2017.00906

Shaul-Keinan, O., Gadkar, V., Ginzberg, I., Grünzweig, J. M., Chet, I., Elad, Y., et al. (2002). Hormone concentrations in tobacco roots change during arbuscular mycorrhizal colonization with Glomusintraradices. New Phytol. 1542, 501-507. doi: 10.1046/j.1469-8137.2002.00388.x

Shekoofeh, E., Sepideh, H., and Roya, R. (2012). Role of mycorrhizal fungi and salicylic acid in salinity tolerance of Ocimum basilicum resistance to salinity. Afr. J. Biotechnol. 11, 2223-2235. doi: 10.5897/AJB11.1672

Shelp, B. J., Bozzo, G. G., Trobacher, C. P., Chiu, G., and Bajwa, V. S. (2012). Strategies and tools for studying the metabolism and function of $\gamma$-aminobutyrate in plants. I. Pathway structure. Botany 90, 651-668. doi: 10.1139/b2012-030

Sheng, M., Tang, M., Chen, H., Yang, B., Zhang, F., and Huang, Y. (2008). Influence of arbuscular mycorrhizae on photosynthesis and water status of maize plants under salt stress. Mycorrhiza 18, 287-296. doi: 10.1007/s00572-008-0180-7

Siemens, J. A., and Zwiazek, J. J. (2004). Changes in root water flow properties of solution culture grown trembling aspen (Populus tremuloides) seedlings under different intensities of water-deficit stress. Physiol. Plant 121, 44-49. doi: 10.1111/j.0031-9317.2004.00291.x

Singh, P., Basu, S., and Kumar, G. (2018). "Polyamines metabolism: a way ahead for abiotic stress tolerance in crop plants," in Biochemical, Physiological and Molecular Avenues for Combating Abiotic Stress Tolerance in Plants (Elsevier).

Singh, S., Parihar, P., Singh, R., Singh, V. P., and Prasad, S. M. (2016). Heavy metal tolerance in plants: role of transcriptomics, proteomics, metabolomics, and ionomics. Front. Plant Sci. 6:1143. doi: 10.3389/fpls.2015. 01143

Slocum, R. D., Kaur-Sawhney, R., and Galston, A. W. (1984). The physiology and biochemistry of polyamines in higher plants. Arch. Biochem. Biophys. 235, 283-303. doi: 10.1016/0003-9861(84)90201-7

Smith, S. E., and Read, D. J. (2008). Mycorrhizal Symbiosis. San Diego, CA: Academic Press.

Sonah, H., Deshmukh, R. K., Labbé, C., and Bélanger, R. R. (2017). Analysis of aquaporins in Brassicaceae species reveals high-level of conservation and 
dynamic role against biotic and abiotic stress in canola. Sci. Rep. 7, 1-17. doi: 10.1038/s41598-017-02877-9

Souza, L. A., Camargos, L. S., Schiavinato, M. A., and Andrade, S. A. L. (2014). Mycorrhization alters foliar soluble amino acid composition and influences tolerance to $\mathrm{Pb}$ in Calopogonium mucunoides. Theor. Exp. Plant Physiol. 26, 211-216. doi: 10.1007/s40626-014-0019-x

Srivastava, S., Srivastava, A. K., Suprasanna, P., and D'Souza, S. F. (2013). Quantitative real-time expression profiling of aquaporins-isoforms and growth response of Brassica juncea under arsenite stress. Mol. Biol. Rep. 40, 2879-2886. doi: 10.1007/s11033-012-2303-7

Taie, H. A., El-Yazal, M. A. S., Ahmed, S. M., and Rady, M. M. (2019). Polyamines modulate growth, antioxidant activity, and genomic DNA in heavy metal-stressed wheat plant. Environ. Sci. Pollut. Res. 26, 22338-22350. doi: 10.1007/s11356-019-05555-7

Tailor, A., and Bhatla, S. C. (2021). Polyamine homeostasis modulates plasma membrane-and tonoplast-associated aquaporin expression in etiolated saltstressed sunflower (Helianthus annuus L.) seedlings. Protoplasma 258, 661-672. doi: 10.1007/s00709-020-01589-8

Tailor, A., Tandon, R., and Bhatla, S. C. (2019). Nitric oxide modulates polyamine homeostasis in sunflower seedling cotyledons under salt stress. Plant Signal. Behav. 14:1667730. doi: 10.1080/15592324.2019.1667730

Tajti, J., Janda, T., Majláth, I., Szalai, G., and Pál, M. (2018). Comparative study on the effects of putrescine and spermidine pre-treatment on cadmium stress in wheat. Ecotoxicol. Environ. Saf. 148, 546-554. doi: 10.1016/j.ecoenv.2017.10.068

Talaat, N. B., and Shawky, B. T. (2013). Modulation of nutrient acquisition and polyamine pool in salt-stressed wheat (Triticum aestivum L.) plants inoculated with arbuscular mycorrhizal fungi. Acta Physiol. Plant 3, 2601-2610. doi: 10.1007/s11738-013-1295-9

Tseng, T. Y., Ou, J. F., and Wang, C. Y. (2013). Role of the ascorbateglutathione cycle in paraquat tolerance of rice. Weed Sci. 61, 361-373. doi: 10.1614/WS-D-12-00133.1

Tun, N. N., Santa-Catarina, C., Begum, T., Silveira, V., Handro, W., Floh, E. I. S., et al. (2006). Polyamines induce rapid biosynthesis of nitric oxide (NO) in Arabidopsis thaliana seedlings. Plant Cell Physiol. 47, 346-354. doi: $10.1093 / \mathrm{pcp} / \mathrm{pci} 252$

Uehlein, N., Fileschi, K., Eckert, M., Bienert, G. P., Bertl, A., and Kaldenhoff, R. (2007). Arbuscular mycorrhizal symbiosis and plant aquaporin expression. Phytochemistry 68, 122-129. doi: 10.1016/j.phytochem.2006.09.033

Uehlein, N., Lovisolo, C., Siefritz, F., and Kaldenhoff, R. (2003). The tobacco aquaporin NtAQP1 is a membrane $\mathrm{CO}_{2}$ pore with physiological functions. Nature 425, 734-737. doi: 10.1038/nature02027

Urano, K., Yoshiba, Y., Nanjo, T., Igarashi, Y., Seki, M., Sekiguchi, F., et al. (2003). Characterization of Arabidopsis genes involved in biosynthesis of polyamines in abiotic stress responses and developmental stages. Plant Cell Environ. 26, 1917-1926. doi: 10.1046/j.1365-3040.2003.01108.x

Valot, B., Dieu, M., Recorbet, G., Raes, M., Gianinazzi, S., and DumasGaudot, E. (2005). Identification of membrane-associated proteins regulated by the arbuscular mycorrhizal symbiosis. Plant Mol. Biol. 59, 565-580. doi: 10.1007/s11103-005-8269-2

Vats, S., Sudhakaran, S., Bhardwaj, A., Mandlik, R., Sharma, Y., Kumar, S., et al. (2021). Targeting aquaporins to alleviate hazardous metal (loid) $\mathrm{s}$ imposed stress in plants. J. Hazard. Mater. 408:124910. doi: 10.1016/j.jhazmat.2020.124910

Wang, B., and Qiu, Y. L. (2006). Phylogenetic distribution and evolution of mycorrhizas in land plants. Mycorrhiza 16, 299-363. doi: 10.1007/s00572-005-0033-6

Wang, D., Li, L., Xu, Y., Limwachiranon, J., Li, D., Ban, Z., et al. (2017). Effect of exogenous nitro oxide on chilling tolerance, polyamine, proline, and $\gamma$ aminobutyric acid in Bamboo Shoots (Phyllostachys praecox f. prevernalis). J. Agric. Food Chem. 65, 5607-5613. doi: 10.1021/acs.jafc.7b02091

Wen, X. P., Pang, X. M., Matsuda, N., Kita, M., Inoue, H., Hao, Y. J., et al. (2008). Over-expression of the apple spermidine synthase gene in pear confers multiple abiotic stress tolerance by altering polyamine titers. Transgenic Res. 17, 251-263. doi: 10.1007/s11248-007-9098-7

Wu, J., Shu, S., Li, C., Sun, J., and Guo, S. (2018). Spermidine-mediated hydrogen peroxide signaling enhances the antioxidant capacity of salt-stressed cucumber roots. Plant Physiol. Bioch. 128, 152-162. doi: 10.1016/j.plaphy.2018.05.002
Wu, Q. S., He, X. H., Zou, Y. N., Liu, C. Y., Xiao, J., and Li, Y. (2012b). Arbuscular mycorrhizas alter root system architecture of Citrus tangerine through regulating metabolism of endogenous polyamines. Plant Growth Regul. 68, 27-35. doi: 10.1007/s10725-012-9690-6

Wu, Q. S., Peng, Y. H., Zou, Y. N., and Liu, C. Y. (2010). Exogenous polyamines affect mycorrhizal development of Glomus mosseaecolonized citrus (Citrus tangerine) seedlings. Sci. Asia 36, 254-258. doi: 10.2306/scienceasia1513-1874.2010.36.254

Wu, Q. S., Srivastava, A. K., and Zou, Y. N. (2013). AMF-induced tolerance to drought stress in citrus: a review. Sci. Hortic. 164, 77-87. doi: 10.1016/j.scienta.2013.09.010

Wu, Q. S., Zou, Y. N., Liu, C. Y., and Ting, L. U. (2012a). Interacted effect of arbuscular mycorrhizal fungi and polyamines on root system architecture of citrus seedlings. J. Integr. Agric. 11, 1675-1681. doi: 10.1016/S2095-3119(12)60170-1

Xu, W., Dai, W., Yan, H., Li, S., Shen, H., Chen, Y., et al. (2015). Arabidopsis NIP3; 1 plays an important role in arsenic uptake and root-to-shoot translocation under arsenite stress conditions. Mol. Plant 8, 722-733. doi: 10.1016/j.molp.2015.01.005

Yamaji, N., and Ma, J. F. (2007). Spatial distribution and temporal variation of the rice silicon transporter Lsil. Plant Physiol. 143, 1306-1313. doi: $10.1104 / p p .106 .093005$

Yamasaki, H., and Cohen, M. F. (2006). NO signal at the crossroads: polyamineinduced nitric oxide synthesis in plants? Trends Plant Sci. 11, 522-524. doi: 10.1016/j.tplants.2006.09.009

Yang, H., Shi, G., Wang, H., and Xu, Q. (2010). Involvement of polyamines in adaptation of Potamogeton crispus L. to cadmium stress. Aquat. Toxicol. 100, 282-288. doi: 10.1016/j.aquatox.2010.07.026

Yasmeen, T., Tariq, M., Iqbal, S., Arif, M. S., Riaz, M., Shahzad, S. M., et al. (2019). "Ameliorative capability of plant growth promoting rhizobacteria (PGPR) and arbuscular mycorrhizal fungi (AMF) against salt stress in plant," in Plant Abiotic Stress Tolerance, eds M, M. Hasanuzzaman, K. Hakeem, K. Nahar, and H. Alharby (Cham: Springer), 409-448. doi: 10.1007/978-3-030-06 118-0_17

Yong, Z., Liyuan, X., Bingquan, X., Ming, Z., Jianfu, L., Dong, Y., et al. (2003). Effect of polyamine on growth and development of arbuscular mycorrhizal fungi in vitro culture condition. Mycosystema 22, 417-423.

Zapata, P. J., Serrano, M., Pretel, M. T., Amorós, A., and Botella, M. Á. (2004). Polyamines and ethylene changes during germination of different plant species under salinity. Plant Sci. 167, 781-788. doi: 10.1016/j.plantsci.2004. 05.014

Zhang, F., Zou, Y. N., Wu, Q. S., and Kuča, K. (2020). Arbuscular mycorrhizas modulate root polyamine metabolism to enhance drought tolerance of trifoliate orange. Environ. Exp. Bot. 171:103926. doi: 10.1016/j.envexpbot.2019. 103926

Zhao, X. Q., Mitani, N., Yamaji, N., Shen, R. F., and Ma, J. F. (2010). Involvement of silicon influx transporter OsNIP2; 1 in selenite uptake in rice. Plant Physiol. 153, 1871-1877. doi: 10.1104/pp.110.157867

Zou, Y. N., Wu, H. H., Giri, B., Wu, Q. S., and Kuča, K. (2019). Mycorrhizal symbiosis down-regulates or does not change root aquaporin expression in trifoliate orange under drought stress. Plant Physiol. Biochem. 144, 292-299. doi: 10.1016/j.plaphy.2019.10.001

Zou, Y. N., Zhang, F., Srivastava, A. K., Wu, Q. S., and Kuča, K. (2021). Arbuscular mycorrhizal fungi regulate polyamine homeostasis in roots of trifoliate orange for improved adaptation to soil moisture deficit stress. Front. Plant Sci. 11, 2046-2059. doi: 10.3389/fpls.2020.600792

Conflict of Interest: The authors declare that the research was conducted in the absence of any commercial or financial relationships that could be construed as a potential conflict of interest.

Copyright (c) 2021 Sharma, Gupta, Thokchom, Jangir and Kapoor. This is an openaccess article distributed under the terms of the Creative Commons Attribution License (CC BY). The use, distribution or reproduction in other forums is permitted, provided the original author(s) and the copyright owner(s) are credited and that the original publication in this journal is cited, in accordance with accepted academic practice. No use, distribution or reproduction is permitted which does not comply with these terms. 


\section{GLOSSARY}

ABA, Abscisic Acid; ADC, Arginine Decarboxylase; As, Arsenic; Al, Aluminum; AM, Arbuscular Mycorrhiza; AMF, Arbuscular Mycorrhizal Fungi; APOX, Ascorbate Perroxidase; AQPs, Aquaporins; C, Carbon; Cad, Cadaverine; Cd, Cadmium; CHA, Cyclohexylamine; $\mathrm{Ci}$, Intracellular $\mathrm{CO}_{2}$ Concentration; $\mathrm{Cl}^{-}$, Chloride Ion; cNMP, cyclic Nucleotide Monophosphate; Co, Cobalt; $\mathrm{CO}_{2}$, Carbon Dioxide; Cr, Chromium; $\mathrm{Cu}$, Copper; CuAO, Copper Amine Oxidase; DAO, Diamine Oxidases; DFMA, $\alpha$-Difluoromethyl Arginine; DFMO, $\alpha$-Difluoromethyl Ornithine; DHAR, Dehydroascorbate Reductase; DNA, Deoxyribonucleic Acid; ER, Endoplasmic Reticulum; Fe, Iron; GA, Gibberellic Acid; GABA, Gamma-Aminobutyric Acid; GABAT, Gamma-Aminobutyric Acid Transaminase; Gs, Stomatal Conductance; GSH, Glutathione Reduced; GSSH, Glutathione Oxidized; $\mathrm{H}_{2} \mathrm{O}$, Water; $\mathrm{H}_{2} \mathrm{O}_{2}$, Hydrogen Peroxide; Hg, Mercury; HMs, Heavy Metals; HMT, Heavy Metal Tolerance Gene; $\mathrm{J}_{\mathrm{v}}$, Sap Flow Rate; KIRC, Inward Rectifying $\mathrm{K}^{+}$Channels; $\mathrm{K}_{\mathrm{L}}$, Leaf-Specific Conductivity; $\mathrm{L}_{\mathrm{h}}$, Hydrostatic
Root Hydraulic Conductance; $\mathrm{L}_{\mathrm{o}}$, Root Hydraulic Conductance; $\mathrm{L}_{\mathrm{t}}$, Leaf Temperature; MDHAR, Monodehydroascorbate Reductase; MIPs, Major Intrinsic Proteins; Mn, Manganese; Mo, Molybdenum; MT, Metallothionien; MVBs, Multivesicular Bodies; N, Nitrogen; $\mathrm{Na}^{+}$, Sodium Ion; $\mathrm{NaCl}$, Sodium Chloride; NCED: 9-cis-epoxycarotenoid dioxygenase); $\mathrm{NH}_{2}$, Amine Group; $\mathrm{NH}_{3}$, Ammonia; Ni, Nickel; NIPs, Nodulin-26 like Intrinsic Proteins; NO, Nitric Oxide; ODC, Ornithine Decarboxylase; PAO, Polyamine Oxidase; PAs, Polyamines; Pb, Lead; PCs, Phytochelatins; PGPRs, Plant Growth-Promoting Rhizobacteria; PIPs, Plasma Membrane Intrinsic Proteins; POP, Persistent Organic Pollutants; Put, Putrescine; RNA, Ribonucleic Acid; RWC, Relative Water Content; SA, Salicylic Acid; SAM, SAdenosyl Methionine; SAMDC, SAM Decarboxylase; SAR, Sodium Adsorption Ratio; SIPs, Small Basic Intrinsic Protein; Si, Silicon; Spd, Spermidine; SPDS, Spermidine Synthase; Spm, Spermine; SPMS, Spermine Synthase; TCA, Tricarboxylic Acid Cycle; TGN, Trans-Golgi Network; TIPs, Tonoplast Intrinsic Proteins; WUE, Water-Use Efficiency; Zn, Zinc; $\Psi$, Water Potential. 